\title{
IL-1R1/MyD88 signaling and the inflammasome are essential in pulmonary inflammation and fibrosis in mice
}

\author{
Pamela Gasse, ${ }^{1}$ Caroline Mary, ${ }^{1}$ Isabelle Guenon, ${ }^{2}$ Nicolas Noulin, ${ }^{1,3}$ Sabine Charron, ${ }^{1}$ \\ Silvia Schnyder-Candrian, ${ }^{1}$ Bruno Schnyder, ${ }^{1}$ Shizuo Akira, ${ }^{4}$ Valérie F.J. Quesniaux, ${ }^{1}$ \\ Vincent Lagente, ${ }^{2}$ Bernhard Ryffel, ${ }^{1}$ and Isabelle Couillin 1
}

\begin{abstract}
1'Laboratory of Molecular Immunology and Embryology, University of Orleans and CNRS, Orleans, France. ${ }^{2}$ INSERM U620, Université de Rennes 1 , Rennes, France. ${ }^{3}$ Key-Obs SA, Orleans, France. ${ }^{4}$ Osaka University, Suita, Osaka, Japan.
\end{abstract}

\begin{abstract}
The molecular mechanisms of acute lung injury resulting in inflammation and fibrosis are not well established. Here we investigate the roles of the IL-1 receptor 1 (IL-1R1) and the common adaptor for Toll/IL-1R signal transduction, MyD88, in this process using a murine model of acute pulmonary injury. Bleomycin insult results in expression of neutrophil and lymphocyte chemotactic factors, chronic inflammation, remodeling, and fibrosis. We demonstrate that these end points were attenuated in the lungs of IL-1R1- and MyD88-deficient mice. Further, in bone marrow chimera experiments, bleomycin-induced inflammation required primarily MyD88 signaling from radioresistant resident cells. Exogenous rIL-1 $\beta$ recapitulated a high degree of bleomycin-induced lung pathology, and specific blockade of IL-1R1 by IL-1 receptor antagonist dramatically reduced bleomycin-induced inflammation. Finally, we found that lung IL-1 $\beta$ production and inflammation in response to bleomycin required ASC, an inflammasome adaptor molecule. In conclusion, bleomycin-induced lung pathology required the inflammasome and IL-1R1/MyD88 signaling, and IL-1 represented a critical effector of pathology and therapeutic target of chronic lung inflammation and fibrosis.
\end{abstract}

\section{Introduction}

Idiopathic pulmonary fibrosis (IPF) is a progressive and fatal interstitial pneumonitis of unknown cause characterized by sequential episodes of acute lung injury with subsequent scarring, leading ultimately to respiratory failure, and no effective therapy is available (1). IPF is characterized by alveolar epithelial injury and hyperplasia, inflammatory cell accumulation, fibroblast proliferation, and deposition of extracellular matrix with fibrotic lesions. Bleomycin-induced (BLM-induced) inflammation and fibrosis represent an experimental model for IPF. BLM induces oxidative stress, DNA damage, and apoptosis of alveolar macrophages and epithelial cells, leading to chemokine and proinflammatory cytokine secretion, inflammatory cell recruitment, remodeling, and lung fibrosis $(2,3)$. Tissue injury and acute inflammatory responses lead in human and mouse models to an abnormal repair process with dysregulation of the balance between MMPs and their inhibitors, the tissue inhibitors of metalloproteinases (TIMPs), resulting in degradation of extracellular matrix components and accumulation of collagen with progression to pulmonary fibrosis (4-6). Chronic inflammation and/or the profibrotic cytokine network activate proliferation of fibroblasts and myofibroblasts, producing MMPs and TIMPs and resulting in disruption of alveolar structure and loss of lung function (7). Circulating fibrocytes derived from bone marrow progenitor cells also contribute to the pathogenesis of pulmonary fibrosis $(8,9)$.

Nonstandard abbreviations used: BAL, bronchoalveolar lavage; BALF, BAL fluid; BLM, bleomycin; IL-1R1, IL-1 receptor 1; IL-1Ra, IL-1 receptor antagonist; KC, keratinocyte-derived chemokine; MPO, myeloperoxidase; rm, recombinant murine; TARC, thymus activation-regulated chemokine; TIMP, tissue inhibitor of metalloproteinase. Conflict of interest: The authors have declared that no conflict of interest exists. Citation for this article: J. Clin. Invest. 117:3786-3799 (2007). doi:10.1172/JCI32285
The molecular mechanisms leading to lung injury and inflammation are largely unknown. The degradation of the extracellular matrix components, such as hyaluronan, collagens may be involved in triggering of the inflammatory response as endogenous danger signals. Hyaluronan activates macrophages, dendritic and endothelial cells mediated through TLR4 (10-12) and TLR2 engagement (13). In vivo, hyaluronan was proposed to regulate injury and repair upon BLM administration, through TLR2, TLR4, and MyD88 signaling (14). Other hypotheses for the inflammatory response upon lung injury include the formation of elastin degradation products with chemotactic function $(15,16)$ or the release of proinflammatory cytokines such as TNF- $\alpha$ or IL-1 (2).

Apoptosis is a crucial step in induction of inflammation and fibrosis, which is mediated by Fas-FasL signaling (17), activating caspase- 1 and -3 and leading to production of cytokine and chemokines (18). Activation of inflammatory caspases in the inflammasome complex is an essential step for the processing and maturation of the proinflammatory cytokines IL-1 $\beta$, IL-18, and IL-33 in response to microbial, stress, or danger signals (19). Upon activation, the inflammasome is formed by a member of the NALP protein family, such as NALP1, NALP2, or NALP3, and the adaptor protein ASC that connects the NALP with caspase-1 (20). Signals and mechanisms leading to inflammasome activation are still poorly understood. The inflammasome is fundamental for microbial detection (19). However, recent findings have demonstrated that the inflammasome is proficient in sensing stress or endogenous danger signals such as extracellular ATP, hypotonic stress, or toxins associated with cell injury $(21,22)$. IL- $1 \beta$ is a proinflammatory cytokine produced by activated macrophages and epithelial cells, inducing the production of chemokines, TNF- $\alpha$, IL-6, or MMPs with neutrophil recruitment and fibroblast proliferation (23-25), features that are closely associated with chronic inflam- 

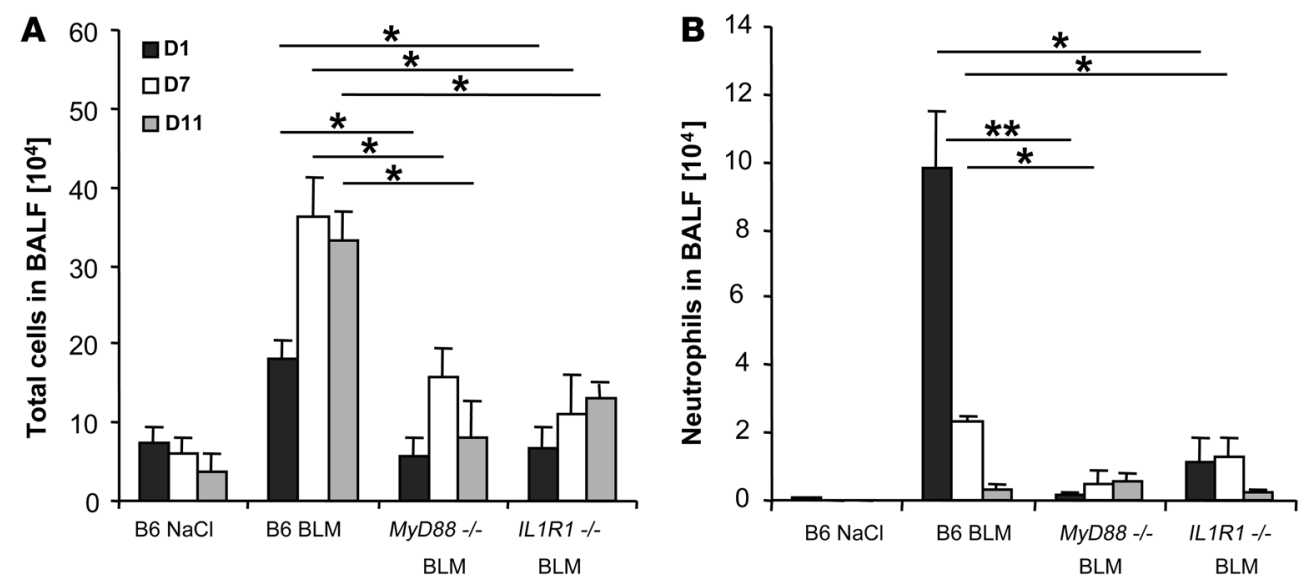

adaptor of IL-1R1, IL-18R, and most TLR signaling pathways, in a series of relevant gene-deficient mice. We report here that BLM-induced acute lung inflammation, remodeling, and fibrosis depended on IL-1R1 and MyD88 signaling, whereas TLR2, TLR4, and IL-18R were dispensable. Further, neutralization of IL- $1 \beta$ by antibody or specific blockage of IL-1R1 antagonist reduced BLM-induced pathology, suggesting a critical role of IL-1
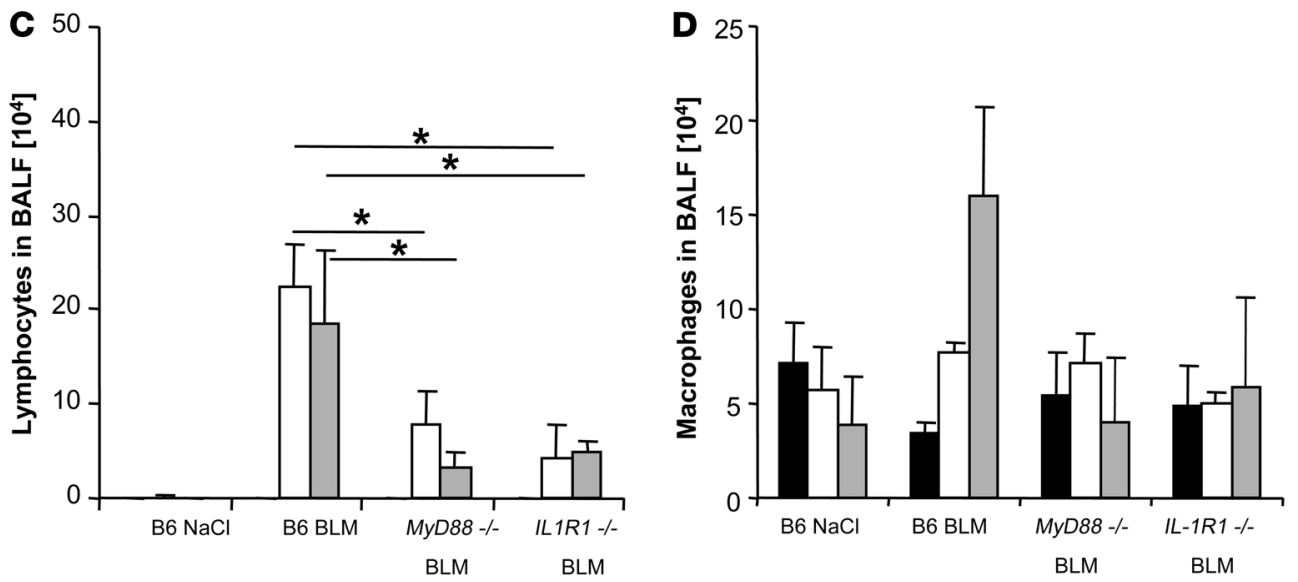

Figure 1

Reduced neutrophil and lymphocyte recruitment in the bronchoalveolar space of BLM-challenged MyD88-/and $I L-1 R 1^{-/-}$mice. (A) Total cell counts were augmented at day 1 in BLM-treated WT (B6) mice (15 mg/kg i.n.) and further increased at days 7 and 11 after BLM administration in WT mice, but less so in $M y D 88^{-1-}$ and $I L-1 R 1^{-/-}$mice. (B) Neutrophils were recruited into BALF in WT mice within 24 hours, persisted over 7 days, and normalized on day 11, while only few neutrophils were detected in the absence of MyD88 or IL-1R1. (C) Lymphocytes were found in BALF at day 7 and persisted until day 11 in WT mice and were less prominent in $M y D 88^{-/-}$and $I L-1 R 1^{-/-}$mice. (D) Alveolar macrophages were augmented at day 11 in WT but not $M y D 88^{-/-}$or $I L-1 R 1^{-/-}$mice. Data are from 1 experiment representative of 3 independent experiments $(n=4$ mice per group; ${ }^{\star} P<0.05 ;{ }^{\star \star} P<0.01$ ).

mation and structural changes observed in the lungs of patients with chronic fibrotic lung disease (24). IL-1 family members alter the host response to an inflammatory, infectious, or immunological challenge $(26,27)$. The best known members of this family are IL- $1 \alpha$, IL-1 $\beta$, IL-1 receptor antagonist (IL-1Ra), and IL-18. IL-1 $\alpha$, IL-1 $\beta$, and IL-18 are highly inflammatory cytokines, and dysregulation of their expression can lead to severe pathological effects. IL- $1 \beta$ is produced as an inactive cytoplasmic precursor (pro-IL-1 $\beta$, p35) that must be cleaved to generate the mature active form ( 117$)$. The IL-1 $\beta$-converting enzyme, better known as caspase- 1 , is required for this cleavage (28). IL-1 ligands typically bind to a cellular receptor complex consisting of IL-1 receptor 1 (IL-1R1) and IL-1 receptor accessory protein, with IL-1Ra acting as a natural antagonist of IL- $1 \alpha / \beta$ by trapping IL-1R1 molecules (26).

To further investigate the potential involvement of the innate immune recognition by the TIR family $(29,30)$ in response to BLM injury and development of chronic inflammation and fibrosis, we studied the role of the MyD88 adaptor protein, the common and underlining the potential for such therapies to be effective in pulmonary interstitial diseases. Finally, acute cellular inflammation and IL- $1 \beta$ production in response to BLM are dependent upon the adaptor protein ASC, which is essential for the inflammasome function. These findings provide insights into the molecular processes underlying the inflammatory conditions of BLM-induced lung fibrosis and further support a pivotal role of the inflammasome in idiopathic pulmonary fibrosis and lung injury diseases.

\section{Results}

Neutrophil and lymphocyte recruitment in the bronchoalveolar space are MyD88 and IL-1R1 dependent. MyD88, a critical adaptor molecule for most members of the TLR/IL-1R family, has been reported to be involved in TLRmediated acute lung inflammation $(14,31)$. To further analyze the implications of the different MyD88-dependent pathways in acute lung injury, we evaluated the airway inflammatory cell response by enumerating the cells recruited in the bronchoalveolar lavage fluid (BALF) after i.n. BLM administration. Total cell counts were increased at days 1,7 , and 11 upon BLM administration in C57BL/6 mice but were lower in MyD88-/- and IL-1R1/- mice (Figure $1 \mathrm{~A})$. BLM elicited acute neutrophil recruitment in C57BL/6 mice within 24 hours, which persisted over 7 days and normalized on day 11 (Figure 1B) and was largely reduced in the absence of MyD88 and IL-1R1. Lymphocyte counts were augmented at days 7 and 11 in WT mice but were significantly lower in MyD88 $8^{-/-}$and IL-1R1-/- mice (Figure 1C). Alveolar macrophages recovered in BALF were augmented at day 11 in WT, but not in MyD88 ${ }^{-/-}$or IL-1R1/- mice, although the difference did not reach statistical significance (Figure 1D). Therefore, BLM-induced neutrophil and lymphocyte influx into the bronchoalveolar space is dependent upon IL-1R1/MyD88 signaling. 

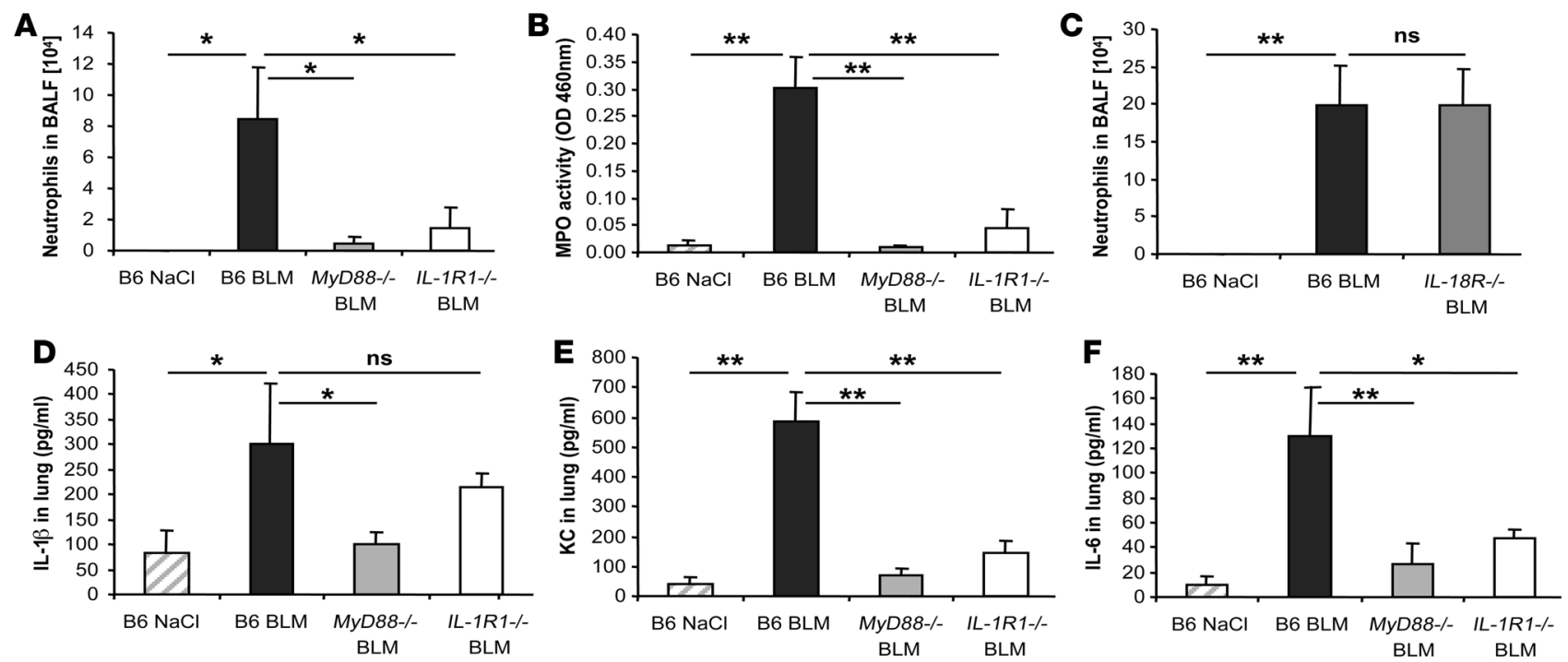

Figure 2

Reduced BLM-induced acute lung inflammation in IL-1R1- and MyD88-deficient mice. IL-1R1- and MyD88-deficient mice showed reduced neutrophil recruitment in BALF (A) and lung tissue (B), whereas IL-18R-deficient mice had neutrophil counts comparable to WT mice (C). BALs were performed 24 hours after BLM instillation (15 mg/kg), and MPO activity was analyzed at day 7 . IL-1 $\beta$ (D), KC (E), and IL-6 (F) in the lung at 24 hours were reduced in IL-1R1- and MyD88-deficient mice as compared with WT mice. Cytokine and chemokine quantification in lung homogenates were performed by multiplex ELISA cytokine arrays (detection limit at $1 \mathrm{pg} / \mathrm{ml}$ ). Data represent mean values \pm SD from 2 independent experiments $\left(n=4\right.$ mice per group; $\left.{ }^{\star} P<0.05 ;{ }^{*} P<0.01\right)$.

BLM-induced neutrophil recruitment in the lung is TLR2, -3, -4, and -9 independent. Since neutrophil recruitment was abrogated in the absence of MyD88, the common adaptor of TLRs, we investigated the role of individual TLRs in BLM-induced acute lung inflammation. Mice deficient for TLR2, TLR4, TLR9, as well as TLR3, the only MyD88-independent TLR, showed abundant neutrophil recruitment 24 hours after BLM administration, with no significant difference in comparison with WT mice (Supplemental Figure 1A; supplemental material available online with this article; doi:10.1172/JCI32285DS1). These data demonstrate that the TLRs tested are dispensable for MyD88-mediated acute neutrophil influx into bronchoalveolar space. To exclude a potential compensation of TLR2 and TLR4, we tested double TLR2/4-deficient mice and found no significant difference from C57BL/6 mice (Supplemental Figure $1 \mathrm{~B})$. Identical results were obtained in the absence of the common adaptor protein for TLR2 and -4, TIRAP, using TIRAP-deficient mice (data not shown). We further examined myeloperoxidase (MPO) activity (Supplemental Figure 1C), expression of neutrophil chemotactic factor keratinocyte-derived chemokine (KC) and IL-6 (Supplemental Figure 1, D and E), and expression of thymus activation-regulated chemokine (TARC), a lymphocyte chemotactic factor (Supplemental Figure 1F), in the lung after BLM-induced lung injury. No significant difference in lung MPO, KC, IL-6, or TARC responses between TLR2/4-deficient and C57BL/6 mice was found. Similar data were obtained for KC, IL-6, and TARC levels in BALF (data not shown). These data demonstrate that TLR-deficient mice, and in particular double TLR2/4-deficient mice, are not protected from BLM-induced lung inflammation, in contrast to MyD88-deficient mice. Therefore, the resistance of MyD88-deficient mice to BLM-induced lung injury appears to be TLR independent, leaving IL-1R-related signaling as a potential pathogenic pathway.

Reduced acute inflammation induced by BLM in IL-1R1-but not in $I L-18 R-$ deficient mice. Acute stress and injury may activate the inflam- masome promoting the processing and secretion of proinflammatory cytokines such as IL-1 and IL-18 $(32,33)$, and IL-1 is increased upon BLM injury (34). Since resistance of MyD88-deficient mice to BLM-induced lung injury was TLR independent, we studied further the implication of the IL-1R family in BLM-induced acute lung injury. In fact, IL-1R1-deficient mice display a dramatic reduction of neutrophil recruitment into the bronchoalveolar space at day 1 after BLM administration (Figure 2A). Pulmonary MPO activity at day 7 was elevated only in C57BL/ 6 mice but in neither IL-1R1- nor MyD88-deficient mice (Figure 2B). No neutrophils were found in either mouse group after saline administration.

Since IL- 1 and TNF- $\alpha$ share proinflammatory properties, we investigated the participation of TNF- $\alpha$, a cytokine that does not use the MyD88 adaptor protein for signaling, using TNF- $\alpha$-deficient mice (35). The inflammatory response of TNF- $\alpha$-deficient mice to BLM was not significantly different from that of C57BL/ 6 mice in terms of increased total cell influx into BALF, induced neutrophil influx into BALF and lung, or KC- and IL-6-enhanced production in lung, suggesting that TNF- $\alpha$ is dispensable for the inflammatory response to BLM (Supplemental Figure 2, A-E).

Further, IL-1 $\beta$ is produced in the lung upon BLM administration (Figure 2D), while IL-18 was not detectable by ELISA (data not shown). IL-1 and IL-18 signal through IL-1R1 and IL-18R, respectively, which belong to the IL-1 receptor subfamily and use the adaptor MyD88 protein (36). To exclude any contribution by the IL-18R pathway in the MyD88-dependent BLM-induced lung injury, we investigated the response of IL-18R $\mathrm{R}^{-/-}$mice. Unlike IL-1R1-/- and MyD88-/- mice, IL-18R ${ }^{-/-}$mice responded with a strong neutrophil influx to BLM (Figure 2C). Therefore, IL-18R is dispensable for acute neutrophil influx into the bronchoalveolar space, showing that IL-1R1, but not IL-18R, signaling is criti$\mathrm{cal}$ in the MyD88-mediated pulmonary inflammatory response to BLM injury. 

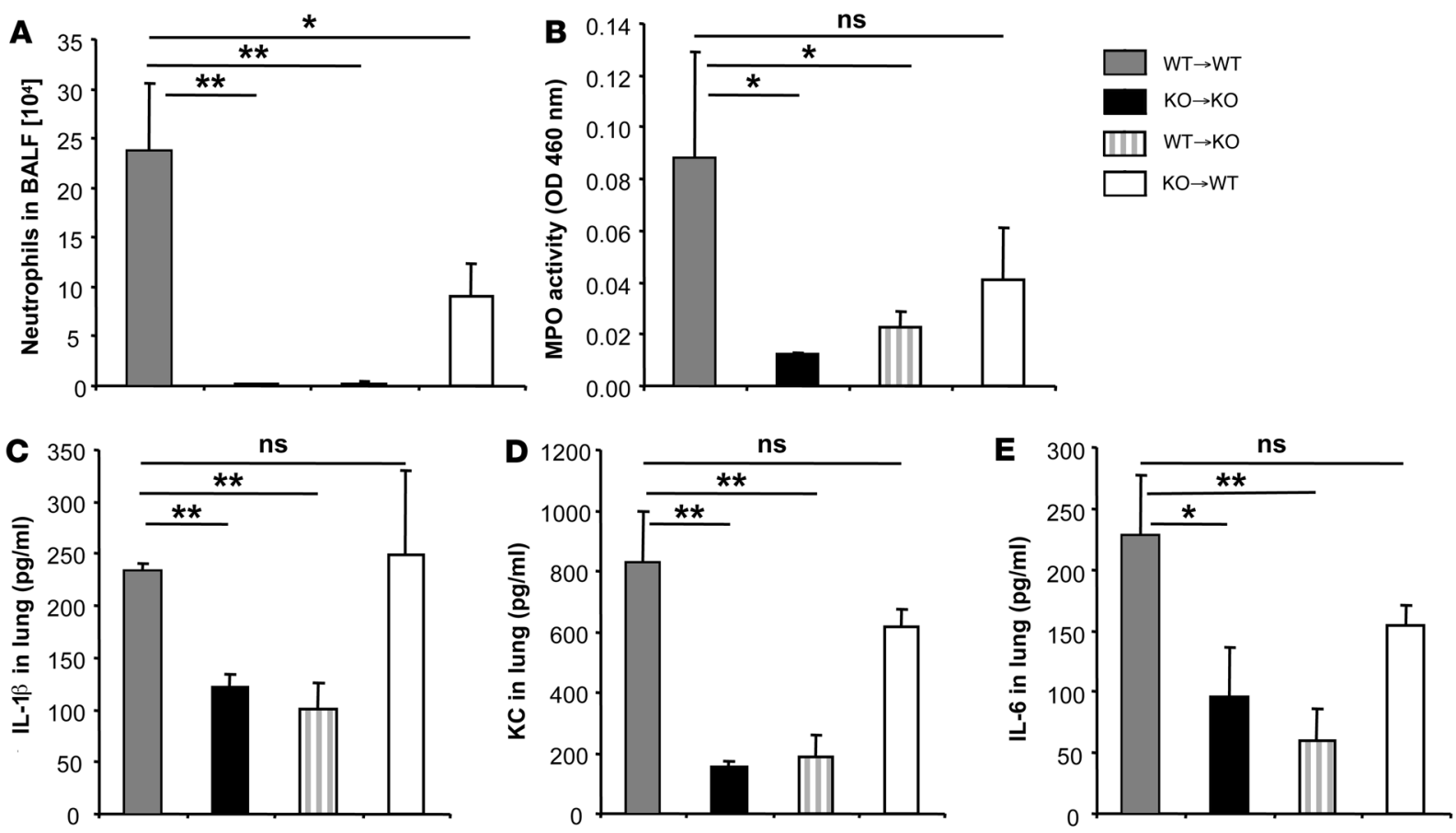

Figure 3

Resident radioresistant cells mediate BLM-induced acute inflammation into lung and bronchoalveolar space. Bone marrow chimeras were prepared by lethal irradiation of either WT or $M y D 88^{-/}$mice, followed by bone marrow cell reconstitution. WT bone marrow reconstitution of

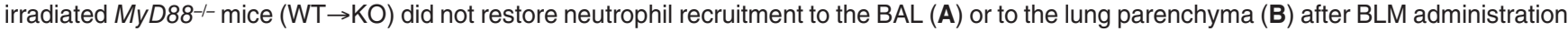
$\left(15 \mathrm{mg} / \mathrm{kg}\right.$ i.n.). Irradiated WT mice reconstituted with $M y D 88^{-/-}$bone marrow $(\mathrm{KO} \rightarrow \mathrm{WT})$ displayed reduced neutrophil influx in BAL $(\mathbf{A})$ and lung parenchyma $(B)$ compared with WT controls $(\mathrm{WT} \rightarrow \mathrm{WT})$. WT bone marrow reconstitution of irradiated MyD88 ${ }^{-/}$mice $(\mathrm{WT} \rightarrow \mathrm{KO})$ did not restore IL-1 $\beta$ (C), KC (D), or IL-6 (E) productions in lung parenchyma. Neutrophil recruitment into the BAL, MPO activity (measured as optical density $[O D])$, and cytokine and chemokine lung levels were evaluated 24 hours after BLM administration, as described above. Data represent mean values \pm SD from 2 independent experiments ( $n=4$ mice per group; ${ }^{*} P<0.05$; ${ }^{\star *} P<0.01$; ns, not significant).

The induction of cytokines and chemokines involved in neutrophil recruitment was evaluated in BALF and lung homogenates of C57BL/ 6 WT and MyD88- and IL-1R1-deficient mice. IL-1 $\beta$ was augmented in the lung at 24 hours after BLM administration (Figure 2D) in C57BL/ 6 control and IL-1R1-deficient mice but not in MyD88-deficient mice, which displayed baseline levels. These data suggest that the production of IL- $1 \beta$ is also dependent on MyD88 pathways other than IL-1R1. Other IL-1-related family receptors, in particular ST2 (the IL-33 receptor) and IL-1Rrp2, also signal through MyD88 and could play a role in BLM-induced IL-1 $\beta$ production and inflammation $(37,38)$. MyD88 was also recently implicated in IFN- $\gamma$ R-induced inflammation (39).

The production of the neutrophil chemotactic factor KC (Figure 2E) and another inflammatory cytokine, IL-6 (Figure 2F), were induced in response to BLM in the lung of $\mathrm{C} 57 \mathrm{BL} / 6$ mice but were dramatically reduced in MyD88/-- and IL-1R1//- mice. Comparable results were obtained in the BALF (data not shown). Therefore, BLM-induced IL- $1 \beta$ secretion and IL-1R1 and MyD88 signaling are required for the production of KC and IL- 6 and for neutrophil recruitment into the lung tissue and bronchoalveolar space.

Resident cells mediate BLM-induced acute neutrophil recruitment as well as IL-1, IL-6, and KC production into the lung. Since IL-1R1/MyD88 is expressed on a broad range of cells, we next addressed the respective role of bone marrow-derived cells and lung resident cells in the BLM response using mixed bone marrow chimeric mice (31). C57BL/6 WT bone marrow reconstitution of $\mathrm{MyD}^{-/-}$mice
$(\mathrm{WT} \rightarrow \mathrm{KO}$ ) did not restore neutrophil recruitment to the bronchoalveolar lavage (BAL) in response to BLM (Figure 3A), while WT mice reconstituted with $\mathrm{MyD} 88^{-/-}$bone marrow $(\mathrm{KO} \rightarrow \mathrm{WT})$ displayed a significant but reduced neutrophil influx in BAL (Figure 3A). Furthermore, WT bone marrow reconstitution of MyD88-$(\mathrm{WT} \rightarrow \mathrm{KO}$ ) did not restore neutrophil recruitment into the lung parenchyma as assessed by MPO activity in lung homogenate after BLM (Figure 3B). By contrast, WT mice reconstituted with $\mathrm{MyD} 88^{-/-}$bone marrow $(\mathrm{KO} \rightarrow \mathrm{WT}$ ) had increased MPO activity, although it was reduced in comparison with irradiated and reconstituted WT mice (WT $\rightarrow$ WT) (Figure 3B). Therefore, neutrophil recruitment in the lung tissue and bronchoalveolar space in response to BLM largely depends on MyD88 signaling in radioresistant resident lung cells, but some contribution of hemopoietic cells is needed for optimal neutrophil influx.

We next determined the chemokine and cytokine production in lung homogenates from chimeric mice. WT bone marrow reconstitution of MyD88-deficient (WT $\rightarrow \mathrm{KO}$ ) mice after BLM administration did not restore IL-1 $\beta$ production in lung tissue (Figure $3 \mathrm{C}$ ), which remained at the level of $\mathrm{MyD}^{-/-}$mice $(\mathrm{KO} \rightarrow \mathrm{KO})$. In contrast, WT mice reconstituted with $\mathrm{MyD} 88^{-/-}$bone marrow $(\mathrm{KO} \rightarrow$ WT) had IL-1 $\beta$ production in lung tissue comparable with that of WT controls (WT $\rightarrow$ WT) (Figure $3 \mathrm{C}$ ), indicating that the radioresistant resident cells are responsible for most IL- $1 \beta$ production in response to BLM administration. Furthermore, WT bone marrow reconstitution of $\mathrm{MyD}^{-/-}$mice $(\mathrm{WT} \rightarrow \mathrm{KO}$ ) after BLM adminis- 

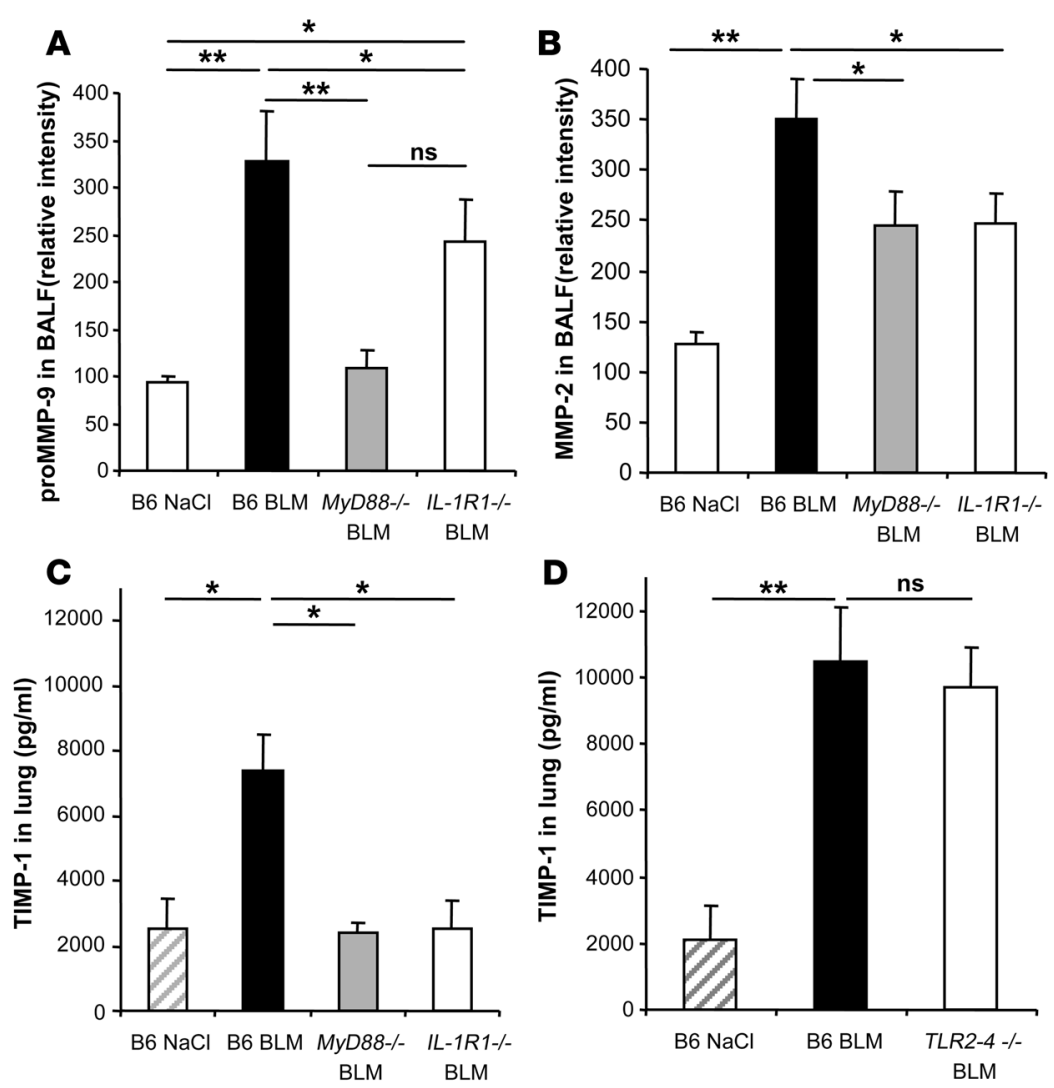

\section{Figure 4}

BLM-induced lung tissue remodeling is IL-1R1 and MyD88 dependent. pro-MMP-9 (99 kDa) and MMP-2 $(71 \mathrm{kDa})$ activities in BALF were analyzed by zymography 1 and 11 days after administration of BLM (15 $\mathrm{mg} / \mathrm{kg}$ i.n.). Pro-MMP-9 was upregulated in the BALF of WT mice 24 hours after BLM administration and returned to normal levels at day 11 , whereas MMP-2 was upregulated only at day 11 after BLM administration (data not shown). (A) Pro-MMP-9 activity was not upregulated in the BALF of $M y D 88^{-/-}$mice and only partially in $I L-1 R 1^{-/-}$mice 24 hours after BLM administration. (B) MMP-2 was upregulated by BLM in the BALF of WT mice, but less so in $M y D 88^{-/-}$and

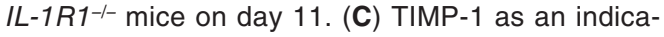
tor of a fibrotic process was upregulated in the lungs of WT but not $M y D 88^{-/-}$or IL-1R1-/- mice at 24 hours after BLM administration (15 mg/kg). (D) TIMP-1 concentrations were also increased in TLR2 and TLR4 double-deficient mice. TIMP-1 levels were assessed by ELISA, and data represent mean values \pm SD from 2 independent experiments $(n=4$ mice per group; $\left.{ }^{*} P<0.05 ;{ }^{* *} P<0.01\right)$. tration did not restore KC or IL-6 production in lung tissue (Figure 3, D and $\mathrm{E}$ ), which remained at the level of $\mathrm{MyD}^{-1-}$ mice $(\mathrm{KO} \rightarrow \mathrm{KO})$. WT mice reconstituted with $\mathrm{MyD} 88^{-/-}$bone marrow $(\mathrm{KO} \rightarrow \mathrm{WT})$ had increased $\mathrm{KC}$ and IL-6 production in lungs, which was superior to that of $\mathrm{MyD} 88^{-/-}$mice but slightly lower than that of WT controls (WT $\rightarrow$ WT) (Figure 3, D and E). Altogether, the results from mixed bone marrow chimera suggest that BLM induced neutrophil recruitment in the lung and that IL-1 $\beta, \mathrm{KC}$, and IL- 6 productions are mediated by IL-1R1/MyD8 8 signaling mainly by a radioresistant, nonhemopoietic cell type that cannot be restored by bone marrow cell reconstitution.

Remodeling process induced by BLM injury is IL-1R 1 and MyD88 dependent. We extended our analysis of BLM-induced injury and fibrosis by evaluating remodeling factors during the repair process. The gelatinase activities were assessed by the measurement of MMP-9 (gelatinase A) and MMP-2 (gelatinase B) by zymography. MMP-9 $(99 \mathrm{kDa})$ is largely produced by neutrophils, and its activity is associated with neutrophil recruitment (40). MMP-9 activity was significantly upregulated in BALF at day 1 in C57BL/6 mice but not in $\mathrm{MyD} 88^{-/-}$mice, and only partially in IL-1R1/- mice (Figure 4A). These data suggest that the increase in MMP-9 may also be dependent on MyD88 pathways other than IL-1R1. MMP-9 activity returned to baseline level at day 11 (data not shown), whereas MMP-2 (76 kDa) activity was elevated only at day 11 in C57BL/6 mice but not in $\mathrm{MyD} 88^{-/-}$and IL-1R1-/- mice (Figure 4B). Since the balance of tissue inhibitors of metalloproteinase (TIMPs) and MMPs is an important factor in the fibrotic process, we analyzed the production of TIMP-1. TIMP-1 activity was upregulated in BALF (data not shown) and lung homogenates of C57BL/6 and TLR2/4-/-, but not MyD88 ${ }^{-/-}$or IL-1R1 $1^{-/}$, mice within 24 hours
(Figure 4, C and D). Therefore, the data suggest that IL-1R1/ MyD88 signaling is required for MMP-9, MMP-2, and TIMP-1 activation and contributes to fibrosis.

Attenuation of BLM-induced lung fibrosis in IL-1R1- and MyD88-deficient mice. The net result of BLM-induced tissue injury is chronic inflammation and progressive pulmonary fibrosis. Microscopic investigations at 7 days after BLM administration showed acute inflammatory reactions in the lungs and signs of fibrosis in C57BL/6 mice. The hallmarks of the pathology are severe alveolitis with abundant neutrophils in the alveoli, recruitment of mononuclear cells, and destruction and repair with thickening of the alveolar septae. On day 11, the lung sections also showed extensive fibrotic areas with abundant collagen production (Figure 5B), as compared with normal alveolar structure of the saline controls (Figure 5A). Cellular infiltrates, alveolar wall destruction, and collagen deposition were significantly reduced in IL-1R1-/- (Figure $5 \mathrm{D}$ ) and MyD88 $8^{-/-}$mice (Figure $5 \mathrm{E}$ ), but not in TLR2 $/ 4^{-/-}$mice (Figure 5C). The inflammatory and fibrotic morphological alterations as assessed semiquantitatively were significantly reduced in the absence of IL-1R1/MyD88 (data not shown). Moreover, biochemically significant collagen deposition in the lung tissue of C57BL/6 mice, but not IL1-R1 $1 /$ - (Figure $5 \mathrm{~F}$ ) or MyD88 $8^{-/}$mice (data not shown), was found. TGF- $\beta 1$, a critical mediator of remodeling and fibrotic responses in the lung, was evaluated at different time points after BLM administration. Latent TGF- $\beta 1$ was detected after activation in BALF from WT mice 7 days after BLM administration, but was not detected in BALF from MyD88or IL-1R1-deficient mice (Figure 5G), and persisted until day 14 in WT mice (53 pg/ml). Active TGF- $\beta 1$ was undetectable in BALF from WT and deficient mice probably due to lower production 

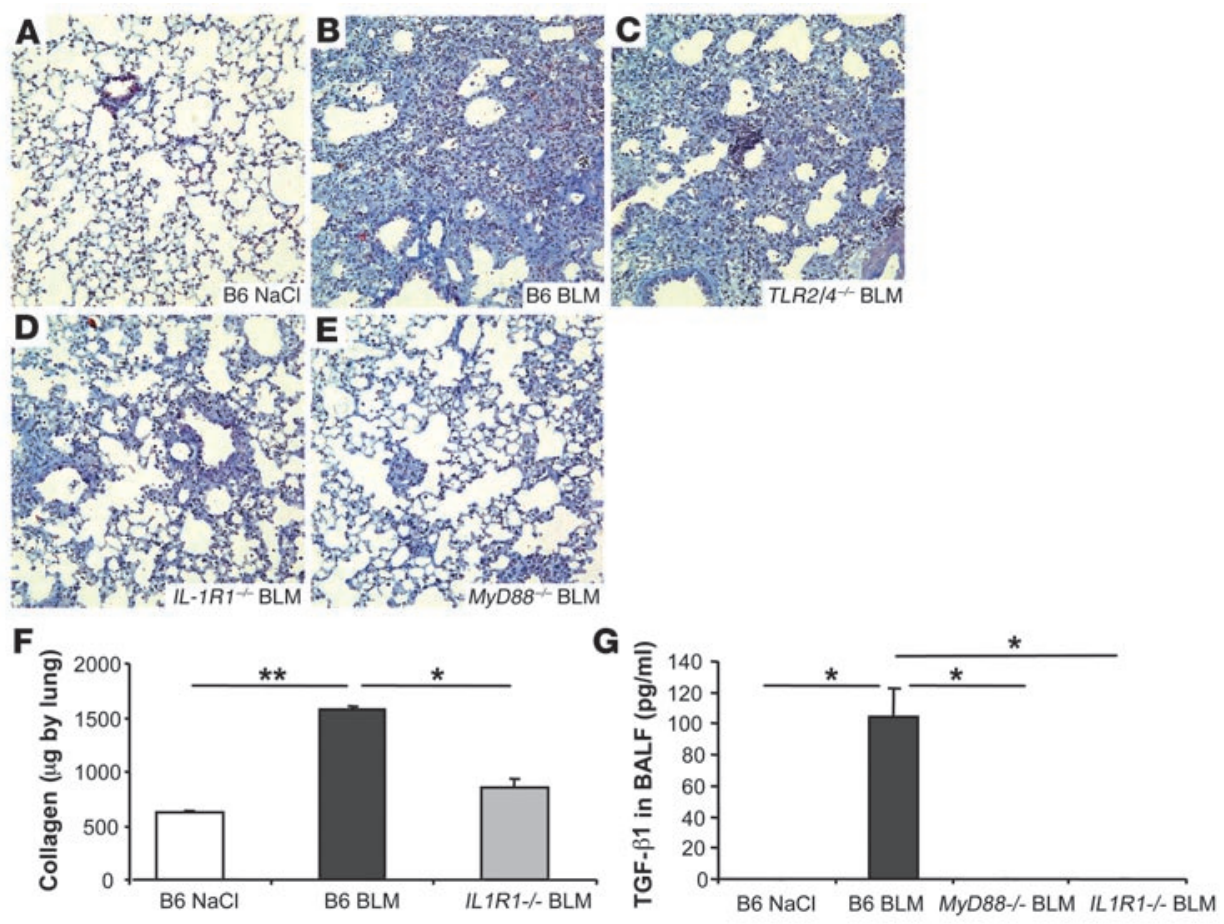

\section{Figure 5}

Reduced pulmonary fibrosis in IL-1R1and MyD88-deficient mice. Lung microscopic sections showed extensive fibrotic areas at day 11 with collagen deposition in WT mice (B) and TLR2 and TLR4 double-deficient mice (C) treated with BLM (15 mg/kg i.n.) in comparison with saline control mice (A). Fibrosis was significantly reduced in IL-1R1-/- mice (D) and in MyD88-/mice (E) treated with BLM. Chromotrope Aniline Blue staining; magnification, $\times 200 ; n=8$ mice). Pulmonary collagen content was increased in WT mice, but not in $I L 1-R 1^{-/-}$mice $(\mathbf{F})$, as determined by Sircol assay. The latent form of TGF- $\beta 1$ was present in BALF from WT mice 7 days after BLM but was undetectable in BALF from MyD88- and IL-1R1-deficient mice as determined by ELISA assay (G). Data represent mean values \pm SD from 3 independent experiments $(n=4$ mice per group; $\left.{ }^{\star} P<0.05 ;{ }^{\star *} P<0.01\right)$. (data not shown). Therefore, IL-1R1/MyD88 signaling is required for the development of pulmonary inflammation, fibrosis, and collagen deposition in response to BLM.

Exogenous IL-1 $\beta$ causes acute and late lung inflammation, remodeling, and fibrosis. In order to confirm that IL- $1 \beta$ is central in BLMinduced acute inflammatory response, we first analyzed the effects of exogenous recombinant murine IL-1 $\beta$ (rmIL-1 $\beta$ ). Mice treated with rmIL-1 $\beta$ presented a very transient and modest body weight loss in comparison with BLM-treated mice. A single i.n. rmIL-1 $\beta$ administration resulted in acute neutrophil recruitment into BALF at 24 hours in WT mice (Figure 6A), while other cell types were essentially not affected (data not shown). As expected, neutrophil recruitment in the BALF of IL-1R1- and MyD88-deficient mice was impaired after i.n. rmIL-1 $\beta$, whereas it was dramatically increased in TLR2/4-, and TNF- $\alpha$-deficient mice, suggesting that TLR2/4 signaling and TNF- $\alpha$ regulate inflammatory response to IL-1 $\beta$ (Figure 6A). Neutrophil influx into lung measured by lung MPO activity was impaired in IL-1R1- and MyD88-deficient mice after i.n. rmIL-1 $\beta$ but not in TLR2/4- and TNF- $\alpha$-deficient mice (Figure 6B). Administration of rmIL-1 $\beta$ also enhanced the expression of neutrophil chemotactic factor CXCL1 (KC), IL-6, and TARC at 24 hours (Figure 6, C-E) in the lung of C57BL/6, TLR2/4-/-, and TNF- $\alpha^{-/-}$mice but not in IL-1R1 $1 /-$ or MyD88 $8^{-/-}$mice. Therefore, exogenous IL-1 $\beta$ induced acute inflammation with neutrophil influx, KC, IL-6, and TARC expression dependent on IL-1R1 and MyD88 but not on TLR2/4 or TNF- $\alpha$ receptor signaling, which resembles the pathology induced by BLM.

To further assess the role of IL-1 $\beta$ in the development of lung fibrosis, we analyzed the effect of exogenous rmIL-1 $\beta$ on the remodeling process. Indeed, 24 hours after IL- $1 \beta$ instillation, MMP-9 activity was upregulated in the BALF of C57BL/6, TLR2/4-/-, and TNF- $\alpha^{-/-}$mice but not MyD88-/- or IL-1R1 1 -- mice (Figure 6F). TIMP-1 activity, the hallmark of evolution to pulmonary fibrosis, was dramatically upregulated by rmIL- $1 \beta$ within 24 hours in lung homogenates of C57BL/6, TLR2/4-/-, and TNF- $\alpha^{-/-}$ mice but not $\mathrm{MyD} 88^{-/-}$or IL-1R1//- mice (Figure $6 \mathrm{G}$ ). Similar results were obtained in the BALF of these mice (data not shown). Therefore, exogenous IL- $1 \beta$ induced MMP-9 and TIMP- 1 activation, which depended on IL-1R1/MyD88 but not TLR2/4 signaling or the presence of TNF- $\alpha$. TIMP- 1 production in WT mice was more transient after a single exogenous IL- $1 \beta$ administration than after BLM and was reduced at day 7 (data not shown). Moreover, we were unable to detect latent TGF- $\beta 1$ in BALF from WT mice after i.n. rIL- $1 \beta$ at day 1,7 , and 14 , whereas latent TGF- $\beta 1$ was detected 7 days after BLM administration (Figure 5G) and was still present at day 14. A single i.n. rmIL-1 $\beta$ administration resulted in significant lymphocyte recruitment into BALF in WT mice at 7 days as seen with BLM (Figure 7A). Moreover, the pulmonary collagen deposition was increased by rmIL-1 $\beta$, although to a lower level than after BLM treatment (Figure 7B). Histological analysis of the lung revealed that within 7 days of administration IL-1 $\beta$ caused tissue injury with marked tissue destruction, disruption of alveolar architecture, inflammation, and fibrosis (although less pronounced than that obtained after BLM treatment; Figure 7, D and E) that was absent in saline controls (Figure 7C) and in the lungs of IL-1R1/- and MyD88/-- mice (data not shown). Further collagen accumulation was observed 14 days after rmIL- $1 \beta$ and after BLM administration (Figure 7, G and $\mathrm{H}$ ), in comparison with saline treatment (Figure 7F). Therefore, rmIL-1 $\beta$ caused a clear but moderate pulmonary fibrosis, suggesting a critical role for endogenous IL-1 in BLM-induced inflammation and fibrosis.

Neutralization of IL-1 reduces acute lung inflammation and remodeling induced by BLM. To confirm that IL- $1 \beta$ is a critical mediator of BLM-induced lung pathology, IL-1 $\beta$ neutralizing antibodies and IL-1Ra were given i.p. at the time of BLM administration. The IL-1 $\beta$ neutralizing antibodies reduced neutrophil recruitment in the BALF as well as KC and IL-6 production in the lung at day 1 (data not shown). IL-1Ra dramatically reduced neutrophil influx 
A
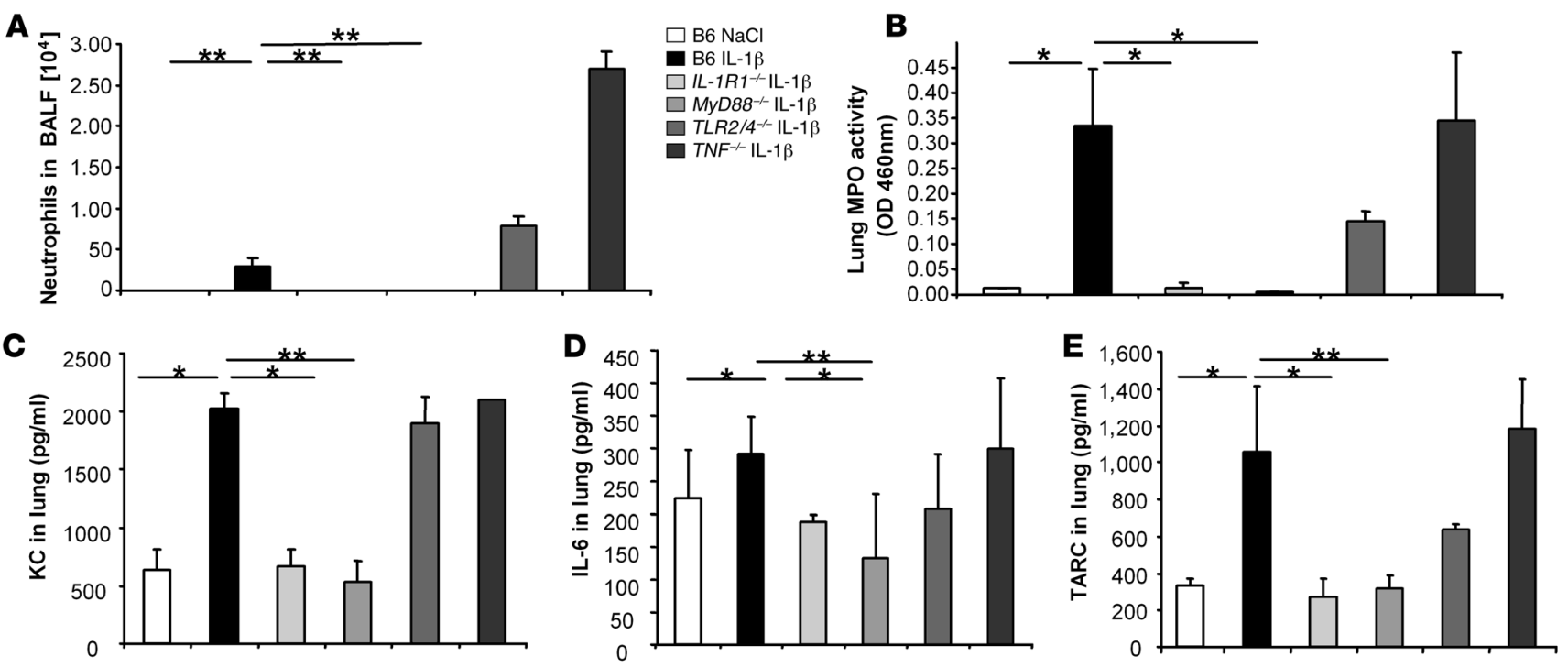

$\mathbf{F}$
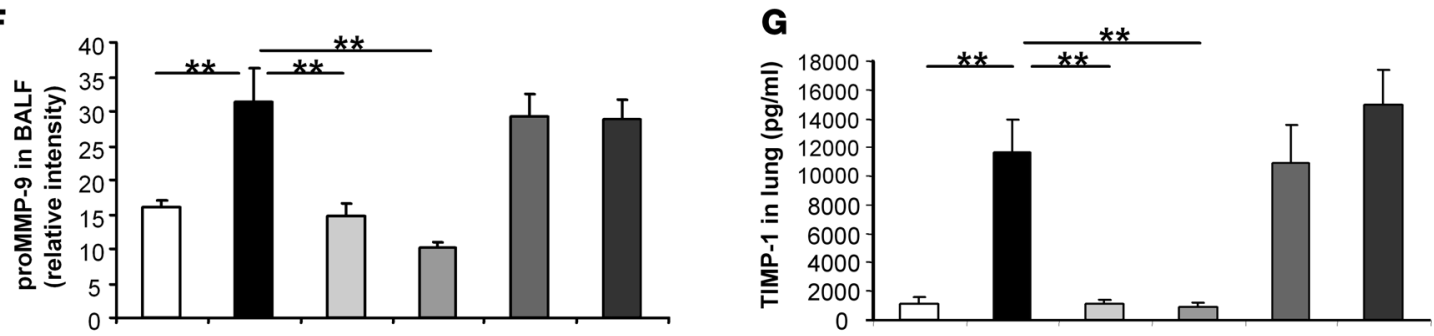

Figure 6

Exogenous IL- $1 \beta$ induces acute lung inflammation and lung tissue remodeling comparable to BLM. One i.n. rmIL- $1 \beta$ administration ( $1 \mu \mathrm{g}$ per mouse, i.e., $0.05 \mathrm{mg} / \mathrm{kg}$ ) induced acute neutrophil recruitment into BALF (A) and lung (B) in WT, TLR2/4-1-, and TNF- $\alpha^{-/-}$mice within 24 hours but was absent in $/ L-1 R 1^{-/-}$and MyD $88^{-/-}$mice. rmIL-1 $\beta$ induced lung KC (C), IL-6 (D), and TARC (E) in WT, TLR2/4 $4^{-/}$, and TNF- $\alpha^{-/-}$mice but not in $I L-1 R 1^{-/-}$and $M y D 88^{-/-}$mice. Pro-MMP-9 (103 kDa) (F) and TIMP-1 (G) activities were upregulated 24 hours after IL-1 $\beta$ instillation in the BALF of WT, TLR2/4 $4^{--}$, and TNF- $\alpha^{-/-}$mice but not of $I L-1 R 1^{-/-}$and $M y D 88^{-/-}$mice. Data represent mean values \pm SD from 2 independent experiments ( $n=4$ mice per group; $\left.{ }^{\star} P<0.05 ;{ }^{*} P<0.01\right)$.

into BALF at day 1 (Figure 8A). Interestingly, IL-1Ra was even more effective than IL-1 $\beta$ neutralizing antibodies in inhibiting neutrophil recruitment in the BALF at day 1 (Figure 8A) and day 14 (Figure $8 \mathrm{~B}$ ). Total cells were also significantly reduced at days 1 and 14 by IL-1Ra (data not shown). IL-1 $\beta, \mathrm{KC}$, and IL- 6 levels in lung were also inhibited by IL-1Ra at day 1 (Figure 8, C-E). Importantly, TIMP-1 was also dramatically reduced in lung (Figure 8F) and BALF (data not shown) after IL-1Ra treatment. Therefore, IL-1 is a key effector cytokine of the BLM-induced fibrotic lung pathology and may represent a critical therapeutic target.

BLM-induced acute inflammation is attenuated in ASC-deficient mice. Acute stress and injury induced by BLM may activate the inflammasome promoting the processing and secretion of proinflammatory cytokines such as IL-1 $\beta$. We showed that IL-1 $\beta$ is increased and essential in BLM-induced lung inflammation and fibrosis. Therefore, we hypothesized that the inflammasome may be critical in BLM-induced acute lung injury. In fact, mice deficient for the adaptor molecule ASC, shared by NALP1-3, display an important reduction of total cell influx (Figure 9A) and neutrophil recruitment (Figure 9B) into the bronchoalveolar space at day 1 after BLM administration. Pulmonary MPO activity at day 1 was elevated only in $\mathrm{ASC}^{+/+}$mice but was significantly reduced in $\mathrm{ASC}^{-/-}$mice
(Figure 9C). Interestingly, reduction of neutrophil influx was less important in $\mathrm{ASC}^{-/-}$than in IL-1R1-/- mice, suggesting that IL-1 $\alpha$ may also play a role in BLM-induced inflammation. IL- $1 \beta$ production into the lung was attenuated in $\mathrm{ASC}^{-/-}$in comparison with $\mathrm{ASC}^{+/+}$control littermates 24 hours after BLM administration (Figure 9D). Since both pro-IL-1 $\beta$ and IL-1 $\beta$ can be detected by this method, residual amount of cytokine measured in $\mathrm{ASC}^{-/-}$mice might correspond to the pro-IL- $1 \beta$ form. IL- 6 production into the lung 24 hours after BLM treatment was attenuated in $\mathrm{ASC}^{-/-}$in comparison with $\mathrm{ASC}^{+/+}$control littermates (Figure 9E). Comparable reductions of IL- $1 \beta$ and IL- 6 were obtained in the BALF (data not shown). Therefore, BLM-induced cellular inflammation and IL- $1 \beta$ and IL- 6 productions are dependent upon the ASC inflammasome adaptor molecule, which is required for optimal lung inflammation in response to BLM.

\section{Discussion}

We show here that the acute lung injury induced by BLM administration led to the production of IL-1 $\beta$, inflammation, remodeling, and fibrosis and was dependent upon IL-1R1/MyD88 signaling. Indeed, lung pathology was significantly reduced in IL-1R1- and MyD88-deficient mice, pointing to the essential role 

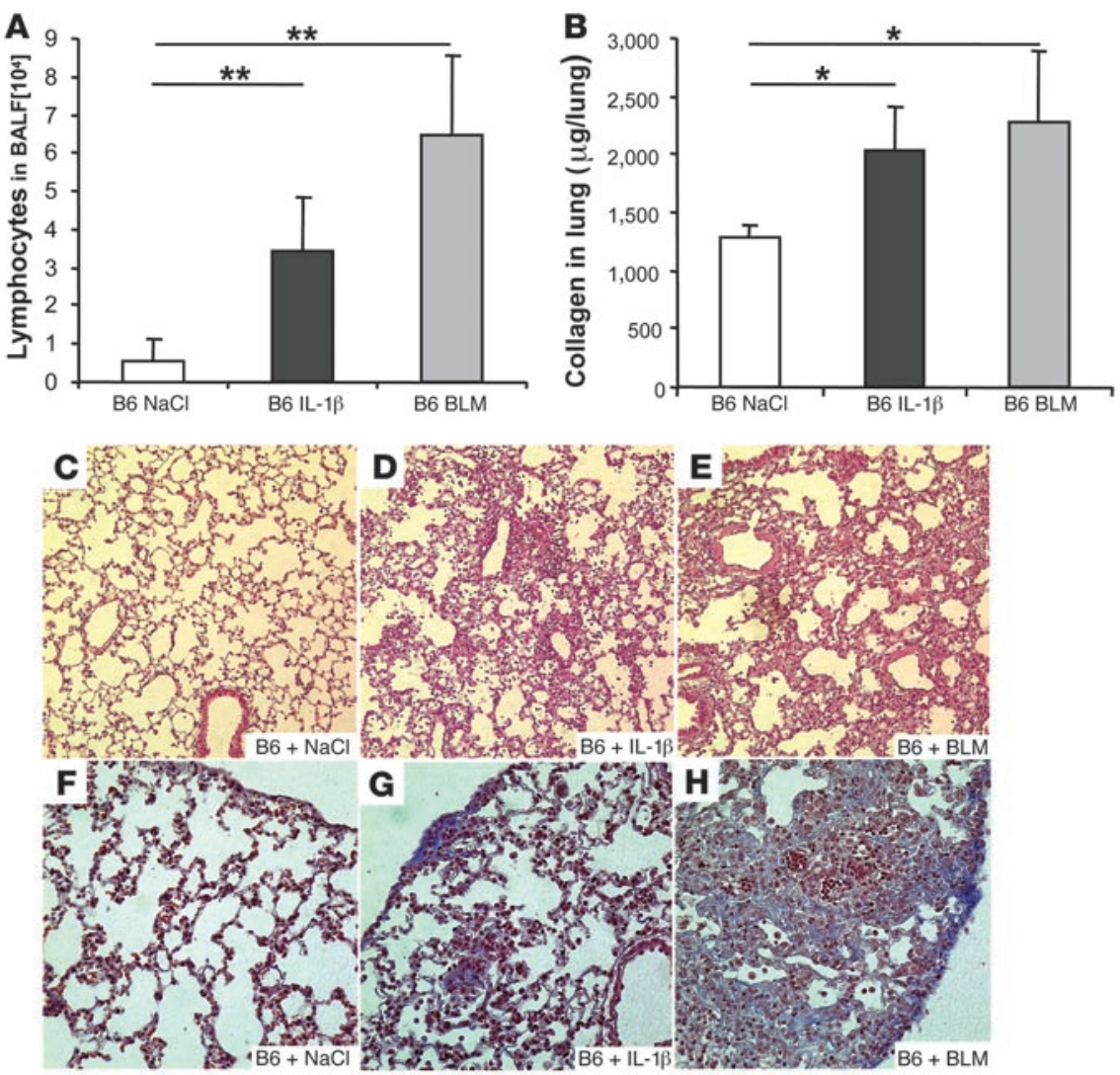

\section{Figure 7}

IL-1 $\beta$ induced lymphocyte inflammation, collagen deposition, and fibrotic disease. (A) Lymphocyte recruitment into BALF was induced at day 7 in WT mice after by 1 i.n. rmIL-1 $\beta$ administration ( $1 \mu \mathrm{g}$ per mouse, i.e., $0.05 \mathrm{mg} / \mathrm{kg}$ ), as for BLM (15 mg/kg i.n.). (B) Pulmonary collagen content (Sircol assay) was increased 7 days after rmIL-1 $\beta$, similar to results from BLM administration. Microscopic analysis revealed tissue injury with disruption of alveolar architecture and repair in lung 7 days after IL-1 $\beta$ administration (D), similar to that induced by $\operatorname{BLM}(15 \mathrm{mg} / \mathrm{kg})(\mathbf{E})$, which was absent in control WT mice (C). H\&E staining (magnification, $\times 200$ ). Tissue and subpleural accumulation of collagen was observed 14 days after IL-1 $\beta$ (G) or BLM (H) administration, in comparison with saline-treated control mice (F). Chromotrope Aniline Blue staining (magnification, $\times 400$ ). The biochemical results represent mean values \pm SD from 2 independent experiments $\left(n=4\right.$ mice per group; $\left.{ }^{*} P<0.05 ;{ }^{* *} P<0.01\right)$. of endogenous IL-1 in pulmonary inflammation and fibrosis in response to BLM. Confirming that IL- 1 acts as a critical mediator, we show that exogenous rmIL-1 $\beta$ recapitulates acute inflammation with alveolar tissue destruction and remodeling, resulting in progressive interstitial fibrosis. The data suggest that BLMmediated lung injury, inflammation, and fibrosis depend upon IL-1R1 and MyD88 signaling. Importantly, IL-1R1 blockade by the IL-1Ra anakinra attenuates the inflammatory pathology. Finally, both lung IL-1 $\beta$ production and acute inflammation upon BLM administration are dependent on the presence of the ASC adaptor molecule, supporting a critical role of the inflammasome in BLMinduced lung injury.

BLM causes lung tissue cell stress and damage, which may lead to the degradation of the extracellular matrix glycosaminoglycan hyaluronan, elastin, collagens, and other matrix components, inducing inflammation. Degradation of extracellular matrix upon tissue injury recently attracted substantial interest for the molecular mechanisms of inflammation (41). Hyaluronan produced upon BLM injury induces inflammation that is perpetuated in the absence of the hyaluronan scavenger receptor CD44 (42). High- and low-molecular fragments seem to have different biological effects (41). Since both TLR2 and TLR4 are activated by hyaluronan in vitro $(10-13,43)$, hyaluronan-dependent TLR activation may play a role in in vivo inflammation and repair. Here we examine the requirement of individual TLRs for lung inflammation and repair upon BLM exposure. Our data using TLR-deficient mice show that TLR2, $-3,-4$, and -9 and notably, combined TLR2/4 signaling, are dispensable for BLM lung injury. Therefore, we confirm that neutrophil recruitment in the airways is dependent upon
MyD88 signaling but are not able to demonstrate the TLR2/4 dependence reported previously in response to BLM (14). Indeed, Jiang et al. (14) showed a decrease in cellular inflammation in the bronchoalveolar space but an enhanced lung injury with increased cell accumulation within the interstitium in MyD88- and TLR2/4deficient mice in comparison with WT mice. Our different results could be explained by differences in the dose and the type of BLM used or differences in the genetic background of the genetically modified mouse strains used. A similar discussion on the relative role of TLR2 and TLR4 versus IL-1R1 in MyD88-dependent monosodium urate crystal-induced inflammation is reported in models of gout arthritis (44-46). Therefore the induction of inflammation in response to BLM in mice is TLR2 and TLR4 independent, but this does not exclude a role for TLRs in hyaluronan-mediated regulation of inflammation and fibrosis.

An alternative hypothesis to explain inflammation upon tissue injury is the induction of protease activation, leading to a multitude of peptides including elastin-derived peptides, which have chemoattractive activity, and antibody neutralization of elastin fragments has been shown to prevent inflammation (15). Further, a tripeptide derived from extracellular matrix degradation has been reported to induce CXCR2-dependent lung inflammation (16). In addition, CXCR3 signaling appears to be nonredundant in BLMinduced inflammation and fibrosis (47). Indeed, we show that BLM induced the $\mathrm{CXC}$ chemokine $\mathrm{KC}$, confirming that lung injury release of chemoattractive mediators may enhance inflammation.

Here we demonstrate TLR2- and TLR4-independent, MyD88dependent signaling in BLM-induced lung injury, and we investigate the role of IL-1 and IL-18, both important proinflammatory 

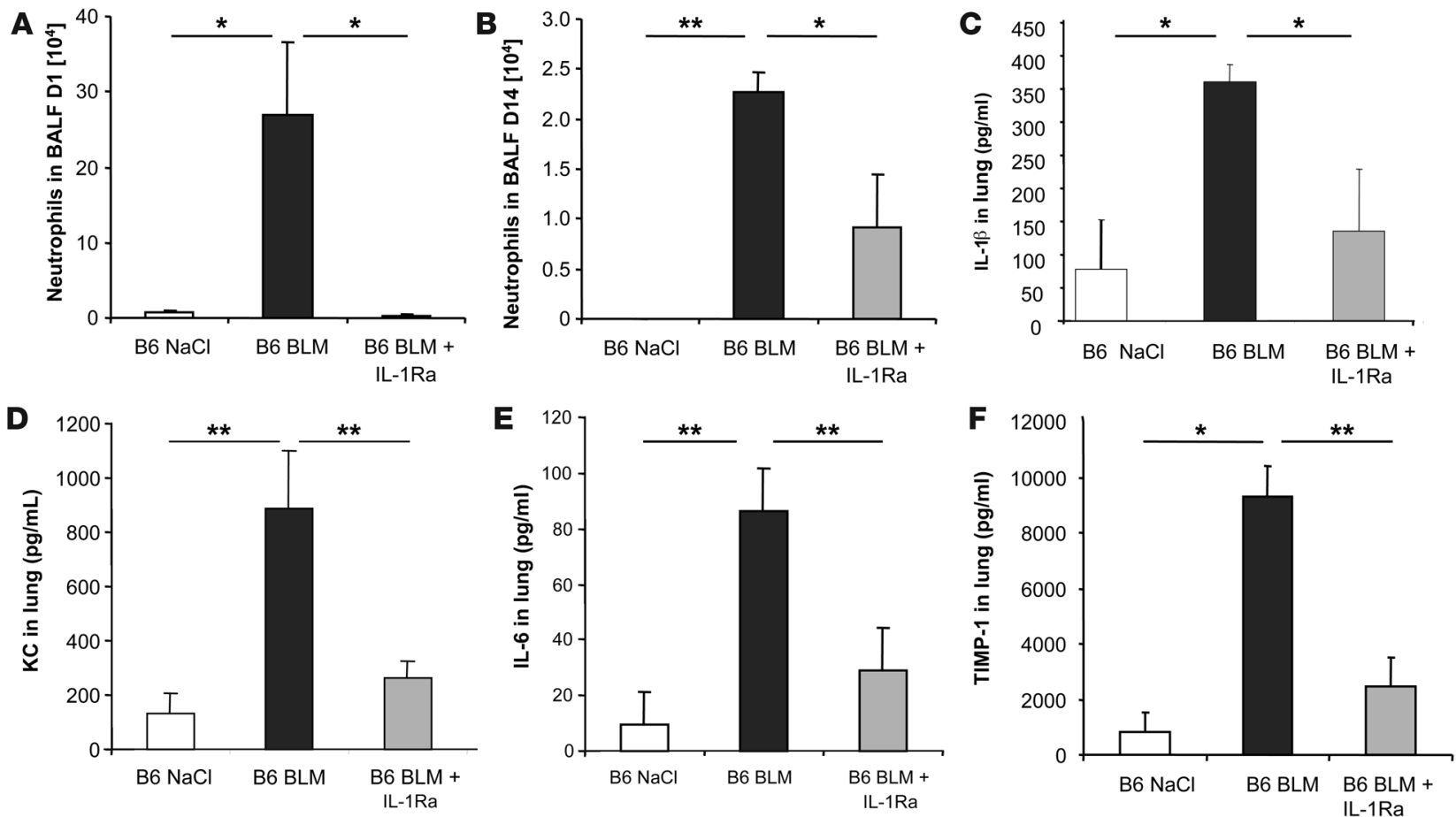

Figure 8

Blockade of IL-1R1 reduces acute lung inflammation. One administration of IL-1Ra (10 mg/kg i.p.) at the time of BLM challenge (15 mg/kg i.n., day 0), dramatically prevented neutrophil recruitment in BALF (A) as well as IL-1 $\beta$ (C), KC (D), and IL-6 (E) production and TIMP-1 expression (F) in the lung measured at day 1. Several administrations of IL-1Ra (1 mg/kg i.p.) on days 0, 2, 4, 7, 9 and 11 after BLM challenge (15 mg/kg i.n., day 0 ) induced a prolonged reduction of neutrophil recruitment in BALF, documented on day 14 (B). Data represent mean values \pm SD from 2 independent experiments $\left(n=4\right.$ mice per group; $\left.{ }^{*} P<0.05 ;{ }^{* *} P<0.01\right)$.

cytokines, using the MyD88 adaptor for their receptor signaling. In fact, we identify IL-1R1 signaling as pivotal for BLM-induced injury, inflammation, and fibrosis, as IL-1R1-deficient mice but not IL-18R-deficient mice were protected. TGF- $\beta 1$, a critical mediator of remodeling and fibrotic responses in the lung, was induced in BALF after BLM administration in WT mice but was undetectable in MyD88- or IL-1R1-deficient mice. We demonstrate that IL-1 $\beta$ is produced upon BLM as reported for injured and apoptotic lung epithelial cells (34). As IL-1 $\beta$ production is decreased in MyD88-deficient mice upon BLM administration, the data suggest MyD88-dependent signaling for IL-1 $\beta$ production. The IL-1 receptor family, in particular ST2, the IL-33 receptor, and IL-1Rrp2, also signal through MyD88 and could play a role in BLM-induced IL-1 $\beta$ production and inflammation $(37,48)$. Moreover, MyD88 was also recently implicated in IFN- $\gamma$ receptor-induced inflammation by stabilizing IFN- $\gamma$ receptor-induced cytokine and chemokine mRNA (39). Alternatively, the IL-1R1/MyD88 pathway might be required for optimal IL- $1 \beta$ production via autocrine or paracrine mechanisms that amplify the response.

Reciprocal MyD88-C57BL/6 bone marrow-chimeric mice suggest that MyD88 signaling in radioresistant resident (probably epithelial) cells, rather than in hemopoietic cells, is essential to initiate the inflammatory response in terms of neutrophil recruitment, IL-1 $\beta$, IL- 6 , and KC production. Nevertheless, hemopoietic cells seem to contribute to optimal neutrophil inflammation, and this could be related to the production of other neutrophil attractants such as eotaxin an MCP-1, which have been implicated in BLM-induced fibrotic changes and could be produced by hemopoietic cells in an IL-1R1/MyD88-dependent manner $(49,50)$. IL-1 $\beta$ induced by BLM in epithelial cells triggers a cascade of biochemical events, resulting in the production of several mediators and chemokines including KC and IL-6, inflammation, remodeling, and fibrosis.

To confirm that IL-1 represents a key mediator of the lung pathology observed, we administered locally to naive mice either IL-1 $\beta$ alone or IL-1 $\beta$-neutralizing antibodies together with BLM. A single i.n. dose of rmIL-1 $\beta$ recapitulated most of the lung injury, inflammation, and repair parameters seen after BLM treatment, suggesting that IL- $1 \beta$ is indeed a key pathogenic factor. To our knowledge, this is the first experimental model demonstrating directly that a single IL- $1 \beta$ administration induces lung inflammation and remodeling, progressing to fibrosis. Nevertheless, IL-1 $\beta$ induces less inflammation, remodeling, and fibrosis than BLM. This may be due to the lower cytotoxicity of IL-1 $\beta$ in comparison to BLM and to the regulation of IL- $1 \beta$ effects, in particular via TNF- $\alpha$ and via TLR2 and TLR4. IL- 1 is a critical inflammatory cytokine and may indeed be responsible for lung pathologies (26). Adenoviral gene transfer of human IL-1 $\beta$ (AdIL-1 $\beta$ ) initiated neutrophil inflammation and fibrosis (51). Further, IL-1 $\beta$ is expressed in chronically inflamed and fibrotic tissues $(26,34,52-54)$. IL-1Ra was reported to prevent or revert pulmonary fibrosis but to have no effect on acute and chronic inflammation elicited in mice by silica or BLM (55). Finally, AdIL- $1 \beta$ together with TNF- $\alpha$ induces TGF- $\beta$ and Smad3, which are critical in fibrogenesis. In fact, absence of $\mathrm{Smad} 3$ abrogates fibrosis induced by AdIL-1 $\beta$ (56). 

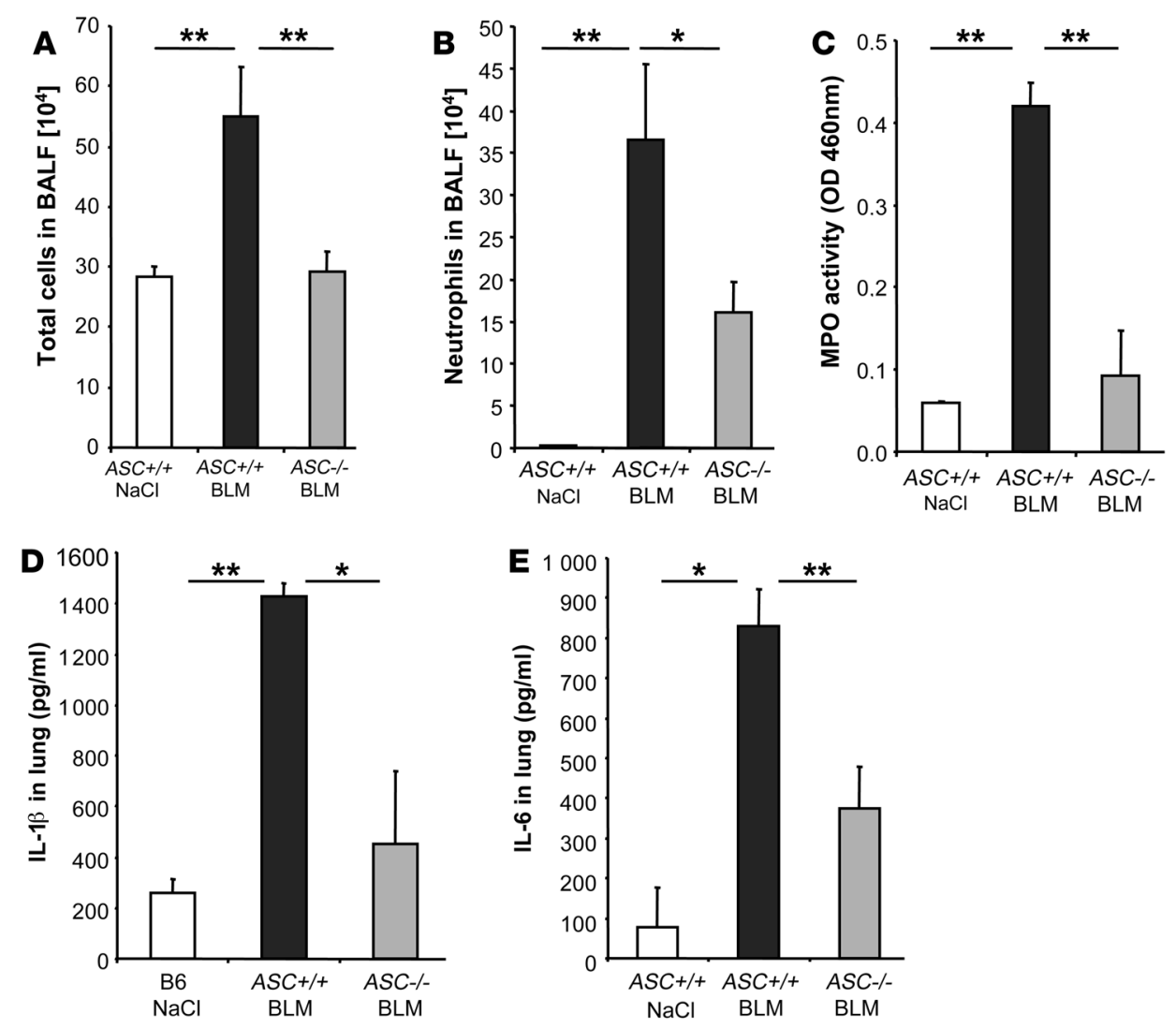

Figure 9

Reduced inflammation upon BLM administration in ASC-deficient mice. ASC-deficient mice showed reduced total cell $(\mathbf{A})$ and neutrophil (B) recruitment in BALF in comparison with littermate control mice after BLM administration (15 mg/kg i.n.). (C) ASC-deficient mice also showed reduced neutrophil influx into the lung tissue in comparison with littermate controls. BALs and MPO activity were analyzed 24 hours after BLM instillation. IL-1 $\beta$ (D) and IL-6 (E) levels in the lung were reduced at 24 hours in ASC-deficient mice as compared with littermate controls. Cytokine and chemokine quantification in lung homogenates were performed by multiplex ELISA cytokine arrays (detection limit at $1 \mathrm{pg} / \mathrm{ml}$ ). Data represent mean values $\pm S D$ from 2 independent experiments $(n=4$ mice per group; $\left.{ }^{\star} P<0.05 ;{ }^{* \star} P<0.01\right)$.
In the BLM model, overt inflammation with tissue damage precedes the repair process, leading to fibrosis, and the pathological process is under the control of several factors. TNF- $\alpha$ and IL-18 were reported to play a role in BLM lung inflammation and fibrosis (57-60), which we could not confirm using TNF- $\alpha$ - and IL-18Rdeficient mice. In particular, TNF- $\alpha$ was believed to be the essential inflammatory cytokine in pulmonary fibrosis and anti-TNF- $\alpha$, but not anti-IL-1, neutralizing therapies were used in clinical trials in the treatment of patients with idiopathic pulmonary fibrosis. Nevertheless, TNF- $\alpha$ seems particularly important in resolving the experimental BLM-mediated inflammation and fibrosis (61). The present results demonstrate that endogenous IL-1 is crucial and nonredundant in BLM induced pathology, rather than TNF- $\alpha$ as proposed before $(57,58,62)$. In fact, exogenous IL- $1 \beta$ recapitulates acute inflammation and remodeling induced by BLM with alveolar tissue destruction, resulting in progressive interstitial fibrosis. Furthermore, several recent reports suggest that phenotypes associated with MyD88 deficiency are not necessarily due to defective TLR signaling but rather to IL-1R1/MyD88 signaling (46, 63-65).

Finally, IL-1R1 blockade with IL-1Ra (anakinra) dramatically attenuated lung inflammation induced by BLM. Previous studies using IL-1Ra treatment in mice reported either an inhibitory effect of IL-1Ra on fibrosis but not on acute or chronic inflammation induced by BLM (55) or no effect of IL-1Ra on BLM-induced fibrosis (66). To our knowledge, no further studies have attempted to resolve this conflict. Nevertheless, there is still no available treatment for idiopathic pulmonary fibrosis, from which patients die 3 or 4 years after the onset of the fibrotic phase. We and others showed that IL-1 $\beta$ is not only a proinflammatory cytokine but is also profibrotic $(25,51)$. IL- $1 \beta$ is associated with autoinflamma- tory and autoimmune diseases in humans and plays a central role during the tissue destructive phase of these diseases. Moreover, IL-1 neutralization is very efficient in treating several destructive diseases such as systemic onset juvenile idiopathic arthritis, hereditary periodic fever syndromes, and gout arthritis (67-74). This illustrates the pleiotropic role of IL-1 $\beta$ and the potential of IL-1 neutralization in the resolution of severe diseases. Our results documenting the prominent role of IL-1 in BLM-induced pulmonary fibrosis in an experimental murine model representing several aspects of idiopathic pulmonary fibrosis are in support of reconsidering IL-1 neutralization in treatment of severe human lung fibrosis.

A crucial part of the innate immune response is the assembly of the inflammasome, a cytosolic complex of proteins that activates caspase- 1 to process the proinflammatory cytokines IL- $1 \beta$ and IL-18. The adaptor protein ASC is essential for inflammasome function, binding directly to caspase- $1(75,76)$. The inflammasome may be involved as a crucial innate sensor of danger signals generated by lung injury, and the new family of pathogen-recognition receptors, the NACHT-LRRs, including NALPs, may have a complementary role to that of TLRs (19). We show here that IL-1 $\beta$ production and lung inflammation in response to BLM are dependent upon the adaptor protein ASC, demonstrating for what we believe to be the first time a pivotal role of the inflammasome in BLM-induced lung injury. Therefore, our data suggest that activation of the inflammasome rather than TLRs is critical to produce mature IL-1 $\beta$ in response to danger signals induced by acute lung injury. We demonstrate that IL-1 $\beta$ maturation by the inflammasome and IL-1R1/MyD88 signaling are crucial steps of innate immune and pathologic responses in lung injury. The 


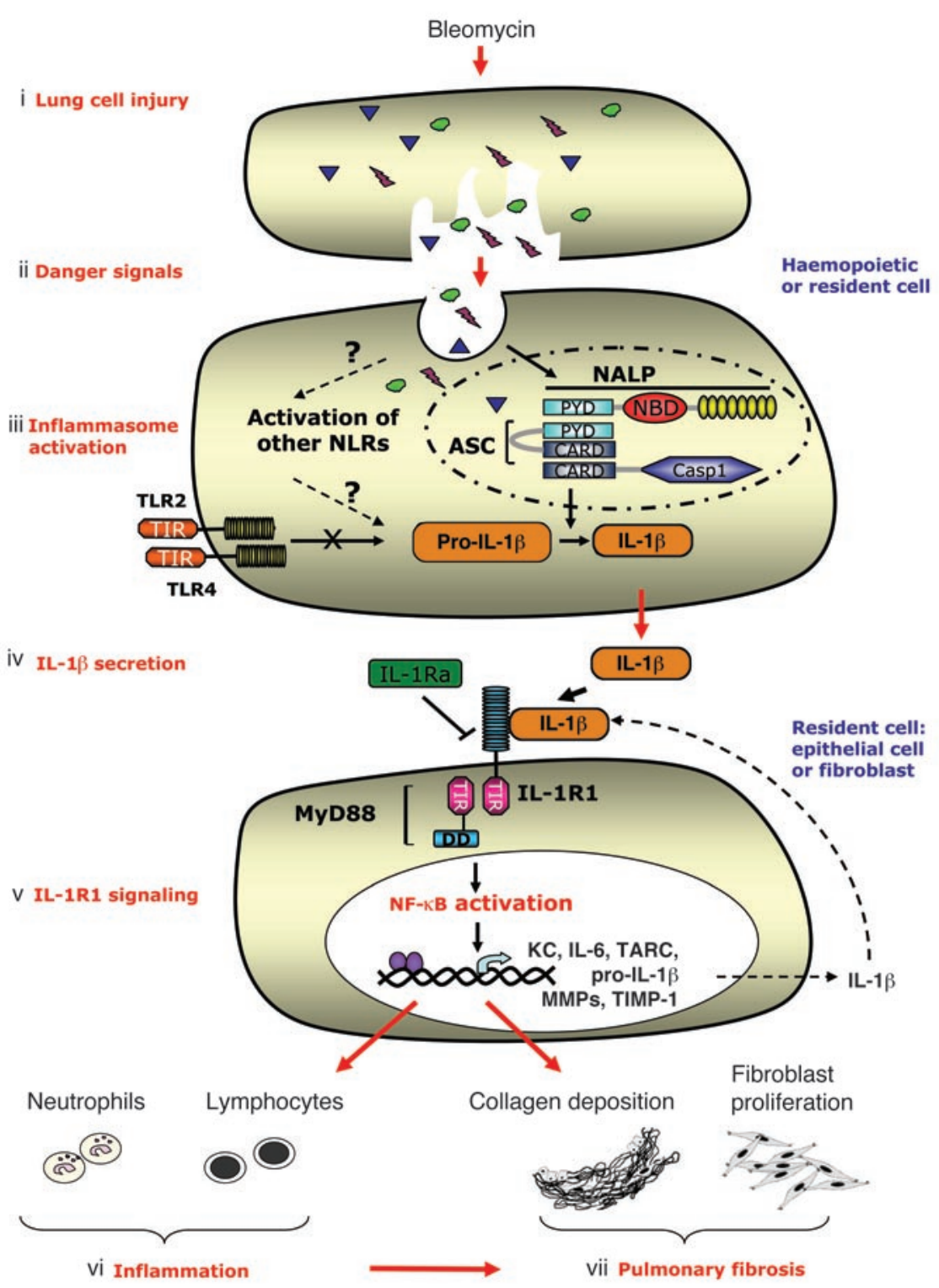

\section{Figure 10}

Schematic diagram illustrating the signaling pathways, cellular sources and the specific cascade after BLM-induced lung injury. (i) BLM induces pulmonary cell injury. (ii) Danger/stress signals generated by dying cells are sensed by the inflammasome rather than TLRs in antigen-presenting cells (alveolar macrophages, dendritic cells, and/or epithelial cells). (iii) Danger signals induce membrane signals, leading probably to the activation of a NALP protein and to the recruitment and activation of the adaptor ASC and caspase-1, known to interact via PYR-PYR and CARDCARD homotypic interactions. (iv) Inflammasome activation results in the processing and maturation of pro-IL-1 $\beta$ into its biologically active form IL-1, and to IL-1 $\beta$ secretion. The production of pro-IL-1 $\beta$ seems independent of TLRs and could be attributed to sensing by other NACHT-LRRs. (v) IL-1 $\beta$ then activates the IL-1R1 complex in tissue-resident cells (probably pulmonary epithelial cells), leading to the recruitment of MyD88 via TIRTIR homotypic interactions. Triggering of the IL-1R1/MyD88 pathway results in the activation of transcription factors such as NF- $\mathrm{KB}$, which will turn on the transcription of neutrophil-attracting chemokines such as KC, lymphocyte-attracting chemokines such as TARC, and the transcription of inflammatory cytokines such as IL-6, resulting in lung inflammation (vi). IL-1R1/MyD88-dependent IL-1 $\beta$ production by tissue-resident cells may contribute to an autocrine/paracrine amplification loop. IL-1R1 blockade with IL-1Ra (anakinra) attenuates lung inflammation induced by BLM. IL-1 $\beta$ will also activate the IL-1R1/MyD88 pathway in fibroblasts, leading to metalloproteinase/TIMP-1 imbalance in favor of TIMP-1 and to fibroblast proliferation, resulting in collagen deposition and pulmonary fibrosis (vii). endogenous danger signals leading to inflammasome activation upon BLM are not known. Our findings open important fields and questions upon the nature of receptors involved in sensing endogenous dangers signals and in assembly of the inflammasome upon lung injury.

In an attempt to summarize our data, we propose the model presented in Figure 10. BLM-induced cell injury results in release and sensing of danger/stress signals by the inflammasome in hemopoietic and/or tissue-resident lung cells. Activation of the inflammasome leads to the processing and maturation of pro-IL- $1 \beta$ into biologically active IL-1 $\beta$, essential for the BLM-induced inflammation, whereas processing of pro-IL-18 into IL-18 is dispensable. IL-1 $\beta$ then activates the IL-1R1/MyD88 complex in tissue-resident cells, probably pulmonary epithelial cells, leading to inflammation with neutrophil and lymphocyte recruitment and to fibroblast activation. Lung fibroblast activation results in metalloproteinase/ TIMP-1 imbalance in favor of TIMP-1 and fibroblast proliferation, yielding to collagen deposition and pulmonary fibrosis.
In conclusion, we implicate the inflammasome rather than TLRs in the sensing of the danger/stress signal, leading to the production of IL- $1 \beta$, and demonstrate that IL- 1 is a critical inflammatory mediator of acute inflammation, remodeling, and fibrosis upon BLM lung injury. Therefore, the data point to a pivotal role of IL-1 in the innate immune response and underline the importance of IL-1 and IL-1R signaling as potential therapeutic targets in inflammatory and fibrotic lung disease. These findings provide insight into the molecular processes underlying the inflammatory conditions of BLM-induced lung fibrosis and further support a pivotal role of the inflammasome in idiopathic pulmonary fibrosis and pulmonary chronic diseases.

\section{Methods}

Mice. MyD88-/- (77), IL-1R1 $1^{-/-}$(78), IL-18R-/- (79), TLR4 ${ }^{-/-}$(80), TLR2 $2^{-/-}$

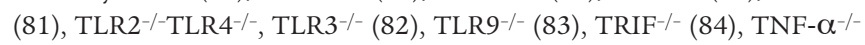

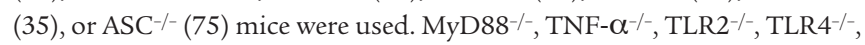
and double-deficient TLR2-/-TLR4-/- mice were backcrossed 10 times 
on the WT C57BL/6 genetic background and 7 times for IL-1R1/- and $\mathrm{TLR}^{-/-}$mice. Littermate controls were used for $\mathrm{ASC}^{-/-}$backcrossed only 3 times on the WT C57BL/ 6 genetic background. All mice, including control

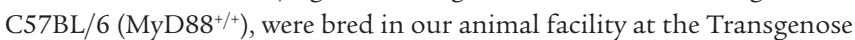
Institute (CNRS, Orleans, France). For experiments, adult (6-10 weeks old) animals were kept in sterile, isolated ventilated cages. All animal experiments complied with the French Government's ethical and animal experiment regulations and were approved by the Comité Régional d'Ethique pour l'Expérimentation Animale (Tours, France). All animals had access to water and food ad libitum before and after exposure.

Administration of BLM, IL-1 $\beta$, IL-1 neutralizing antibody, or IL-1Ra. BLM sulfate $(300 \mu \mathrm{g}$ or $15 \mathrm{mg} / \mathrm{kg})$ from Bellon Laboratories in saline, $\mathrm{mr}$ IL-1 $\beta$ $(0.25 \mu \mathrm{g}$ or $1 \mu \mathrm{g})$ from R\&D Systems in saline, or saline alone were given through the airways by nasal instillation in a volume of $40 \mu \mathrm{l}$ under light ketamine-xylasine anesthesia. The IL- $1 \beta$ neutralizing antibody (provided by H. Gram Novartis Pharma, Basel, Switzerland) and the IL-1Ra (Amgen) were injected at $100 \mu \mathrm{g}$ i.p. at the time of BLM administration.

$B A L F$. After incision of the trachea, a plastic cannula was inserted and airspaces were washed using $0.3 \mathrm{ml}$ of PBS solution heated to $37^{\circ} \mathrm{C}$. The rib cage was then gently massaged to enable maximum cell collection. The fluid was collected by careful aspiration. This procedure was performed 10 times, and the recovery of the total lavage exceeded $95 \%$. The samples collected were dispatched in 2 fractions: the first $(1 \mathrm{ml}$ corresponding to the 2 first lavages) was used for mediator measurement, and the second for the cell determination $(4 \mathrm{ml})$. The first fraction was centrifuged $(600 \mathrm{~g}$ for $10 \mathrm{~min}-$ utes), and supernatant was fractionated and kept at $-80^{\circ} \mathrm{C}$ until mediator determination. The cell pellet was then resuspended in $0.4 \mathrm{ml} \mathrm{PBS}$, pooled with the second fraction, and maintained at $4^{\circ} \mathrm{C}$ until cell determination.

Lung homogenization. After BAL was performed, the whole lung was removed and placed inside a microtube (Lysing matrix D; Q Bio Gene) with $1 \mathrm{ml}$ PBS, total lung tissue extract was prepared using a Fastprep system (FP120, Q Bio Gene), the extract was then centrifuged and the supernatant stored at $-80^{\circ} \mathrm{C}$ before mediator measurement, MPO, or collagen assay with Sircol Collagen Assay (France Biochem Division).

$M P O$ activity in lung. Lung tissue MPO activity was evaluated as described (85). In brief, the right heart ventricle was perfused with saline to flush the vascular content, and lungs were frozen at $-20^{\circ} \mathrm{C}$ until use. Lung was homogenized by polytron and centrifuged, and the supernatant was discarded. The pellets were resuspended in $1 \mathrm{ml}$ PBS containing $0.5 \%$ hexadecyltrimethyl ammonium bromide (HTAB) and 5 mM EDTA. Following centrifugation, $50 \mu \mathrm{l}$ of supernatants were placed in test tubes with 200 $\mu \mathrm{l}$ PBS-HTAB-EDTA, $2 \mathrm{ml}$ Hanks' balanced salt solution (HBSS), $100 \mu \mathrm{l}$ o-dianisidine dihydrochloride $(1.25 \mathrm{mg} / \mathrm{ml})$, and $100 \mu \mathrm{H} \mathrm{H}_{2} \mathrm{O}_{2} 0.05 \%$. After 15 minutes of incubation at $37^{\circ} \mathrm{C}$ in an agitator, the reaction was stopped with $100 \mu \mathrm{l} \mathrm{NaN}_{3} 1 \%$. The MPO activity was determined as absorbance at $460 \mathrm{~nm}$ against medium.

Cell count and determination. Total cell count was determined in BALF using a particle counter (Z2 Coulter; Beckman Coulter). Differential cell counts were performed on cytospin preparations (Cytospin 3; Thermo Shandon) after staining for 4 minutes in May-Grünwald stain (MG-1L; Sigma-Aldrich) and 8 minutes in 95\% Giemsa stain (GS-500; SigmaAldrich). Differential cell counts were made on 100 cells using standard morphological criteria.

Mediator measurements. IL-1 $\beta$, KC, IL-6, TARC, and TIMP-1 levels in BALF or lung homogenate were determined using ELISA assay kits (Mouse DuoSet for IL-1 $\beta$, KC, IL-6, TARC, and TIMP-1; R\&D Systems), except for the experiments described in Figures 2 and 3, according to manufacturer's instructions. For experiments described in Figures 2 and 3, IL-1 $\beta, \mathrm{KC}$, and IL- 6 were measured by multiplex ELISA cytokine arrays with a limit detection of $1 \mathrm{pg} / \mathrm{ml}$ (Upstate Ltd.). TGF- $\beta 1$ levels in BALF were determined using an ELISA kit (Quantikine, mouse, rat, porcine, canine TGF- $\beta 1$ Immunoassay; R\&D Systems).

Bone marrow transplantation to obtain mixed chimera. Recipient mice underwent a lethal total-body irradiation as reported before $(86,87)$. Fresh, unseparated bone marrow cells $\left(2 \times 10^{6}\right.$ per mouse) were injected into the lateral tail vein of the irradiated recipient mice 24 hours after lethal irradiation. Blood was collected in EDTA-containing tubes at regular intervals, and the hematological parameters were determined with a Technikon H1E analyzer. The reconstituted mice were used 3 months after bone marrow transplantation. Further, in some experiments we used GFP-expressing donor cells (88), in order to control the extent of reconstitution, as previously described (31). The current protocol yielded more than $95 \%$ of blood circulating leukocytes of donor origin as assessed by green fluorescence of the peripheral blood using flow cytometry.

Zymographic analysis of MMPs. MMP-2 and MMP-9 levels were determined by gelatin zymography. Briefly, nonreduced supernatant samples of BALF $(15 \mu \mathrm{l})$ and standards (161-0305; Bio-Rad) were loaded onto 7\% polyacrylamide gels (wt/vol) incorporating $0.1 \%(\mathrm{wt} / \mathrm{vol})$ gelatin substrate. Proteins were subjected to electrophoresis at $20-30 \mathrm{~mA}$ for 3 hours. The gel was then washed twice in $2.5 \%$ Triton ( $\mathrm{vol} / \mathrm{vol})$, rinsed 3 times quickly with distilled water, and placed in distilled water 3 times for 20 minutes. Each wash was performed using gentle stirring. Gels were incubated overnight at $37^{\circ} \mathrm{C}$ in $50 \mathrm{mM}$ Tris buffer (containing $5 \mathrm{mM} \mathrm{CaCl}_{2}$ and $2 \mu \mathrm{M} \mathrm{ZnCl}_{2}$ ). Finally, gels were stained in Coomassie Blue and then destained progressively until bands of lysis (enzyme activity) in the gels appeared as regions of negative staining. The areas of lysis were analyzed using a densitometric analyzer (Bio-profil; Vilbert Lourmat), images were taken, and band densities were measured.

Lung collagen measurements. Aliquots of lung homogenate $(50 \mu \mathrm{l})$ were then assayed for lung collagen levels and compared with a standard curve prepared from bovine skin using the Sircol collagen dye binding assay according to the manufacturer's instructions (Biocolor Ltd.).

Histology. After BAL and lung perfusion, the large lobe was fixed in $4 \%$ buffered formaldehyde for standard microscopic analysis. Sections $(3 \mu \mathrm{m})$ were stained with $\mathrm{H} \& \mathrm{E}$ or Chromotrope Aniline Blue as described previously (89). The severity of the morphological changes (infiltration by neutrophils and mononuclear cells and destruction and thickening of the alveolar septae and fibrosis) were assessed semiquantitatively using a score of $0-5$ by 2 independent observers.

Statistics. Statistical evaluation of differences between the experimental groups was determined by Mann-Whitney $U$ test using Prism software. $P$ values of less than 0.05 were considered statistically significant.

\section{Acknowledgments}

We acknowledge the skilled technical assistance of Marielle Maret and Virginie Vasseur. We thank Virginie Pétrilli and Jürk Tschopp for the gift of the ASC-deficient mice strain. The authors are grateful to François Erard for scientific discussion. Grant support was received from the French Ministère de l'Education Nationale, de la Recherche et de la Technologie, the Fondation de la Recherche, and CNRS. The work was also supported by grants from Le Studium and Fondation de la Recherche Médicale.

Received for publication April 2, 2007, and accepted in revised form September 12, 2007.

Address correspondence to: Isabelle Couillin, Molecular Immunology and Embryology, CNRS UMR6218, Transgenose Institute, CNRS, $3 \mathrm{~B}$ rue de la Férollerie, 45071 Orleans, France. Phone: 33-238-25-5439; Fax: 33-238-25-79-79; E-mail: couillin@cnrs-orleans.fr. 
1. Gross, T.J., and Hunninghake, G.W. 2001. Idiopathic pulmonary fibrosis. N. Engl. J. Med. 345:517-525.

2. Piguet, P.F. 1993. Cytokines involved in pulmonary fibrosis. Int. Rev. Exp. Pathol. 34:173-181.

3. Keane, M.P., Strieter, R.M., and Belperio, J.A. 2005. Mechanisms and mediators of pulmonary fibrosis. Crit. Rev. Immunol. 25:429-463.

4. Beeh, K.M., Beier, J., Kornmann, O., and Buhl, R. 2003. Sputum matrix metalloproteinase-9, tissue inhibitor of metalloprotinease-1, and their molar ratio in patients with chronic obstructive pulmonary disease, idiopathic pulmonary fibrosis and healthy subjects. Respir. Med. 97:634-639.

5. Manoury, B., et al. 2005. The absence of reactive oxygen species production protects mice against bleomycin-induced pulmonary fibrosis. Respir. Res. 6:11.

6. Madtes, D.K., Elston, A.L., Kaback, L.A., and Clark, J.G. 2001. Selective induction of tissue inhibitor of metalloproteinase- 1 in bleomycin-induced pulmonary fibrosis. Am. J. Respir. Cell Mol. Biol. 24:599-607.

7. Lagente, V., et al. 2005. Role of matrix metalloproteinases in the development of airway inflammation and remodeling. Braz. J. Med. Biol. Res. 38:1521-1530

8. Hashimoto, N., Jin, H., Liu, T., Chensue, S.W., and Phan, S.H. 2004. Bone marrow-derived progenitor cells in pulmonary fibrosis. J. Clin. Invest. 113:243-252. doi:10.1172/JCI200418847.

9. Phillips, R.J., et al. 2004. Circulating fibrocytes traffic to the lungs in response to CXCL12 and mediate fibrosis. J. Clin. Invest. 114:438-446. doi:10.1172/ JCI200420997.

10. Termeer, C., Sleeman, J.P., and Simon, J.C. 2003 Hyaluronan - magic glue for the regulation of the immune response? Trends Immunol. 24:112-114.

11. Jameson, J.M., Cauvi, G., Sharp, L.L., Witherden, D.A., and Havran, W.L. 2005. Gammadelta T cell-induced hyaluronan production by epithelial cells regulates inflammation. J. Exp. Med. 201:1269-1279.

12. Taylor, K.R., et al. 2004. Hyaluronan fragments stimulate endothelial recognition of injury through TLR4. J. Biol. Chem. 279:17079-17084.

13. Scheibner, K.A., et al. 2006. Hyaluronan fragments act as an endogenous danger signal by engaging TLR2. J. Immunol. 177:1272-1281.

14. Jiang, D., et al. 2005. Regulation of lung injury and repair by Toll-like receptors and hyaluronan. Nat. Med. 11:1173-1179.

15. Houghton, A.M., et al. 2006. Elastin fragments drive disease progression in a murine model of emphysema. J. Clin. Invest. 116:753-759. doi:10.1172/ JCI25617.

16. Weathington, N.M., et al. 2006. A novel peptide CXCR ligand derived from extracellular matrix degradation during airway inflammation. Nat. Med. 12:317-323.

17. Dosreis, G.A., Borges, V.M., and Zin, W.A. 2004. The central role of Fas-ligand cell signaling in inflammatory lung diseases. J. Cell. Mol. Med. 8:285-293.

18. Kuwano, K., et al. 2001. Attenuation of bleomycininduced pneumopathy in mice by a caspase inhibitor. Am. J. Physiol. Lung Cell Mol. Physiol. 280:L316-L325.

19. Martinon, F., and Tschopp, J. 2005. NLRs join TLRs as innate sensors of pathogens. Trends Immunol. 26:447-454.

20. Tschopp, J., Martinon, F., and Burns, K. 2003. NALPs: a novel protein family involved in inflammation. Nat. Rev. Mol. Cell Biol. 4:95-104.

21. Mariathasan, S., et al. 2006. Cryopyrin activates the inflammasome in response to toxins and ATP. Nature. 440:228-232.

22. Martinon, F., Petrilli, V., Mayor, A., Tardivel, A., and Tschopp, J. 2006. Gout-associated uric acid crystals activate the NALP3 inflammasome. Nature. 440:237-241.

23. Barnes, P.J. 2004. Mediators of chronic obstructive pulmonary disease. Pharmacol. Rev. 56:515-548.

24. Sasaki, M., et al. 2000. Differential regulation of metalloproteinase production, proliferation and chemotaxis of human lung fibroblasts by PDGF, interleukin-1beta and TNF-alpha. Mediators Inflamm. 9:155-160.

25. Raines, E.W., Dower, S.K., and Ross, R. 1989. Interleukin-1 mitogenic activity for fibroblasts and smooth muscle cells is due to PDGF-AA. Science. 243:393-396.

26. Dinarello, C.A. 1997. Interleukin-1. Cytokine Growth Factor Rev. 8:253-265.

27. Dunne, A., and O'Neill, L.A. 2003. The interleukin-1 receptor/Toll-like receptor superfamily: signal transduction during inflammation and host defense. Sci. STKE. 2003:re3.

28. Burns, K., Martinon, F., and Tschopp, J. 2003. New insights into the mechanism of IL-1beta maturation. Curr. Opin. Immunol. 15:26-30.

29. Akira, S., Uematsu, S., and Takeuchi, O. 2006. Pathogen recognition and innate immunity. Cell. 124:783-801.

30. Beutler, B., et al. 2006. Genetic analysis of host resistance: toll-like receptor signaling and immunity at large. Annu. Rev. Immunol. 24:353-389.

31. Noulin, N., et al. 2005. Both hemopoietic and resident cells are required for MyD88-dependent pulmonary inflammatory response to inhaled endotoxin. J. Immunol. 175:6861-6869.

32. Ogura, Y., Sutterwala, F.S., and Flavell, R.A. 2006. The inflammasome: first line of the immune response to cell stress. Cell. 126:659-662.

33. Martinon, F., and Glimcher, L.H. 2006. Gout: new insights into an old disease. J. Clin. Invest. 116:2073-2075. doi:10.1172/JCI29404.

34. Cavarra, E., et al. 2004. Early response to bleomycin is characterized by different cytokine and cytokine receptor profiles in lungs. Am. J. Physiol. Lung Cell Mol. Physiol. 287:L1186-L1192.

35. Marino, M.W., et al. 1997. Characterization of tumor necrosis factor-deficient mice. Proc. Natl. Acad. Sci. U. S. A. 94:8093-8098.

36. Martin, M.U., and Wesche, H. 2002. Summary and comparison of the signaling mechanisms of the Toll/interleukin-1 receptor family. Biochim. Biophys. Acta. 1592:265-280

37. Schmitz, J., et al. 2005. IL-33, an interleukin-1-like cytokine that signals via the IL-1 receptor-related protein ST2 and induces T helper type 2-associated cytokines. Immunity. 23:479-490.

38. Towne, J.E., Garka, K.E., Renshaw, B.R., Virca, G.D., and Sims, J.E. 2004. Interleukin (IL)-1F6, IL-1F8, and IL-1F9 signal through IL-1Rrp2 and IL-1RAcP to activate the pathway leading to NF-kappaB and MAPKs. J. Biol. Chem. 279:13677-13688.

39. Sun, D., and Ding, A. 2006. MyD88-mediated stabilization of interferon-gamma-induced cytokine and chemokine mRNA. Nat. Immunol. 7:375-381.

40. Manoury, B., et al. 2006. Macrophage metalloelastase (MMP-12) deficiency does not alter bleomycininduced pulmonary fibrosis in mice. J. Inflamm. (Lond.) 3:2.

41. Noble, P.W., and Jiang, D. 2006. Matrix regulation of lung injury, inflammation, and repair: the role of innate immunity. Proc. Am. Thorac. Soc. 3:401-404.

42. Teder, P., et al. 2002. Resolution of lung inflammation by CD44. Science. 296:155-158.

43. Termeer, C.C., et al. 2000. Oligosaccharides of hyaluronan are potent activators of dendritic cells. J. Immunol. 165:1863-1870.

44. Liu-Bryan, R., and Liote, F. 2005. Monosodium urate and calcium pyrophosphate dihydrate (CPPD) crystals, inflammation, and cellular signaling. Joint Bone Spine. 72:295-302.

45. Scott, P., Ma, H., Viriyakosol, S., Terkeltaub, R., and Liu-Bryan, R. 2006. Engagement of CD14 mediates the inflammatory potential of monosodium urate crystals. J. Immunol. 177:6370-6378.

46. Chen, C.J., et al. 2006. MyD88-dependent IL-1 receptor signaling is essential for gouty inflamma- tion stimulated by monosodium urate crystals. J. Clin. Invest. 116:2262-2271. doi:10.1172/JCI28075.

47. Jiang, D., et al. 2004. Regulation of pulmonary fibrosis by chemokine receptor CXCR3. J. Clin. Invest. 114:291-299. doi:10.1172/JCI200416861.

48. Togbe, D., et al. 2006. TLR4 gene dosage contributes to endotoxin-induced acute respiratory inflammation. J. Lenkoc. Biol. 80:451-457.

49. Huaux, F., et al. 2005. Role of Eotaxin-1 (CCL11) and CC chemokine receptor 3 (CCR3) in bleomycin-induced lung injury and fibrosis. Am. J. Pathol. 167:1485-1496.

50. Yara, S., et al. 2001. FTS reduces bleomycin-induced cytokine and chemokine production and inhibits pulmonary fibrosis in mice. Clin. Exp. Immunol. 124:77-85.

51. Kolb, M., Margetts, P.J., Anthony, D.C., Pitossi, F., and Gauldie, J. 2001. Transient expression of IL-1beta induces acute lung injury and chronic repair leading to pulmonary fibrosis. J. Clin. Invest. 107:1529-1536

52. Pan, L.H., Ohtani, H., Yamauchi, K., and Nagura, H. 1996. Co-expression of TNF alpha and IL-1 beta in human acute pulmonary fibrotic diseases: an immunohistochemical analysis. Pathol. Int. 46:91-99.

53. Phan, S.H., and Kunkel, S.L. 1992. Lung cytokine production in bleomycin-induced pulmonary fibrosis. Exp. Lung Res. 18:29-43.

54. Johnston, C.J., et al. 1996. Early and persistent alterations in the expression of interleukin-1 alpha, interleukin- 1 beta and tumor necrosis factor alpha mRNA levels in fibrosis-resistant and sensitive mice after thoracic irradiation. Radiat. Res. 145:762-767.

55. Piguet, P.F., Vesin, C., Grau, G.E., and Thompson, R.C. 1993. Interleukin 1 receptor antagonist (IL$1 \mathrm{ra}$ ) prevents or cures pulmonary fibrosis elicited in mice by bleomycin or silica. Cytokine. 5:57-61.

56. Bonniaud, P., et al. 2005. TGF-beta and Smad3 signaling link inflammation to chronic fibrogenesis. J. Immunol. 175:5390-5395.

57. Piguet, P.F., et al. 1997. Resistance of TNF/LT alpha double deficient mice to bleomycin-induced fibrosis. Int. J. Exp. Pathol. 78:43-48.

58. Ortiz, L.A., et al. 1998. Expression of TNF and the necessity of TNF receptors in bleomycin-induced lung injury in mice. Exp. Lung Res. 24:721-743.

59. Okamoto, M., et al. 2002. Interleukin 18 (IL-18) in synergy with IL-2 induces lethal lung injury in mice: a potential role for cytokines, chemokines, and natural killer cells in the pathogenesis of interstitial pneumonia. Blood. 99:1289-1298.

60. Fujita, M., et al. 2001. Overexpression of tumor necrosis factor-alpha produces an increase in lung volumes and pulmonary hypertension. Am.J. Physiol. Lung Cell Mol. Physiol. 280:L39-L49.

61. Kuroki, M., et al. 2003. Repression of bleomycin-induced pneumopathy by TNF. J. Immunol. 170:567-574.

62. Miyazaki, Y., et al. 1995. Expression of a tumor necrosis factor-alpha transgene in murine lung causes lymphocytic and fibrosing alveolitis. A mouse model of progressive pulmonary fibrosis. J. Clin. Invest. 96:250-259.

63. Miller, L.S., et al. 2006. MyD88 mediates neutrophil recruitment initiated by IL-1R but not TLR2 activation in immunity against Staphylococcus aureus. Immunity. 24:79-91.

64. Su, S.B., et al. 2005. Essential role of the MyD88 pathway, but nonessential roles of TLRs 2, 4, and 9 , in the adjuvant effect promoting Th1-mediated autoimmunity. J. Immunol. 175:6303-6310.

65. Fremond, C.M., et al. 2007. IL-1 receptor-mediated signal is an essential component of MyD88-dependent innate response to mycobacterium tuberculosis infection. J. Immunol. 179:1178-1189.

66. He, B., Zhao, G.R., and Liu, X.M. 1994. The effect of IL-1 receptor antagonist on bleomycin-induced pulmonary fibrosis [In Chinese]. Zhonghua Jie He He 
Hu Xi Za Zhi. 17:21-23, 61.

67. Hawkins, P.N., Lachmann, H.J., Aganna, E., and McDermott, M.F. 2004. Spectrum of clinical features in Muckle-Wells syndrome and response to anakinra. Arthritis Rheum. 50:607-612.

68. Hoffman, H.M., et al. 2004. Prevention of coldassociated acute inflammation in familial cold autoinflammatory syndrome by interleukin-1 receptor antagonist. Lancet. 364:1779-1785.

69. Fitzgerald, A.A., Leclercq, S.A., Yan, A., Homik, J.E., and Dinarello, C.A. 2005. Rapid responses to anakinra in patients with refractory adult-onset Still's disease. Arthritis Rheum. 52:1794-1803.

70. Pascual, V., Allantaz, F., Arce, E., Punaro, M., and Banchereau, J. 2005. Role of interleukin-1 (IL-1) in the pathogenesis of systemic onset juvenile idiopathic arthritis and clinical response to IL-1 blockade. J. Exp. Med. 201:1479-1486.

71. Matsubara, T., et al. 2006. A severe case of chronic infantile neurologic, cutaneous, articular syndrome treated with biologic agents. Arthritis Rheum. 54:2314-2320.

72. Kalliolias, G.D., Georgiou, P.E., Antonopoulos, I.A., Andonopoulos, A.P., and Liossis, S.N. 2007. Anakinra treatment in patients with adult-onset Still's disease is fast, effective, safe and steroid sparing: experience from an uncontrolled trial. Ann. Rheum. Dis. 66:842-843.
73. So, A., Desmedt, T., Revaz, S., and Tschopp, J. 2007. A pilot study of IL-1 inhibition by anakinra in acute gout. Arthritis Res. Ther. 9:R28.

74. Belkhir, R., et al. 2007. Treatment of familial Mediterranean fever with anakinra. Ann. Intern. Med. 146:825-826.

75. Mariathasan, S., et al. 2004. Differential activation of the inflammasome by caspase- 1 adaptors ASC and Ipaf. Nature. 430:213-218.

76. Martinon, F., Burns, K., and Tschopp, J. 2002. The inflammasome: a molecular platform triggering activation of inflammatory caspases and processing of proIL-beta. Mol. Cell. 10:417-426.

77. Kawai, T., Adachi, O., Ogawa, T., Takeda, K., and Akira, S. 1999. Unresponsiveness of MyD88-deficient mice to endotoxin. Immunity. 11:115-122.

78. Labow, M., et al. 1997. Absence of IL-1 signaling and reduced inflammatory response in IL-1 type I receptor-deficient mice. J. Immunol. 159:2452-2461.

79. Hoshino, K., et al. 1999. Cutting edge: generation of IL-18 receptor-deficient mice: evidence for IL-1 receptor-related protein as an essential IL-18 binding receptor. J. Immunol. 162:5041-5044.

80. Hoshino, K., et al. 1999. Cutting edge: Toll-like receptor 4 (TLR4)-deficient mice are hyporesponsive to lipopolysaccharide: evidence for TLR4 as the Lps gene product. J. Immunol. 162:3749-3752.

81. Takeuchi, O., et al. 1999. Differential roles of
TLR2 and TLR4 in recognition of gram-negative and gram-positive bacterial cell wall components. Immunity. 11:443-451.

82. Alexopoulou, L., Holt, A.C., Medzhitov, R., and Flavell, R.A. 2001. Recognition of double-stranded RNA and activation of NF-kappaB by Toll-like receptor 3. Nature. 413:732-738.

83. Takeshita, F., et al. 2001. Cutting edge: role of tolllike receptor 9 in cpg dna-induced activation of human cells. J. Immunol. 167:3555-3558.

84. Hoebe, K., et al. 2003. Identification of Lps2 as a key transducer of MyD88-independent TIR signalling. Nature. 424:743-748.

85. Arbour, N.C., et al. 2000. TLR4 mutations are associated with endotoxin hyporesponsiveness in humans. Nat. Genet. 25:187-191.

86. Muller, M., et al. 1996. Correction or transfer of immunodeficiency due to TNF-LT alpha deletion by bone marrow transplantation. Mol. Med. 2:247-255.

87. Ryffel, B., et al. 1997. Lack of type $2 \mathrm{~T}$ cell-independent $\mathrm{B}$ cell responses and defect in isotype switching in TNF-lymphotoxin alpha-deficient mice. J. Immunol. 158:2126-2133.

88. Okabe, M., et al. 1997. 'Green mice' as a source of ubiquitous green cells. FEBS Lett. 407:313-319.

89. Couillin, I., et al. 2004. Arthropod-derived histamine-binding protein prevents murine allergic asthma. J. Immunol. 173:3281-3286. 